\title{
The Oriental species of the ant genus Probolomyrmex (Insecta: Hymenoptera: Formicidae: Proceratiinae)
}

\author{
KATSUYUKI EGUCHI ${ }^{1}$, MASASHI YOSHIMURA ${ }^{2} \&$ SEIKI YAMANE $^{3}$ \\ ${ }^{1}$ The Kagoshima University Museum, Kagoshima University, Kagoshima 890-0065, Japan. \\ E-mail: Katsuyuki.Eguchi@mc6.seikyou.ne.jp \\ ${ }^{2}$ Institute of Tropical Agriculture, Kyushu University, Fukuoka 812-8581, Japan. \\ E-mail: myoshimura@ant-database.org \\ ${ }^{3}$ Department of Earth and Environmental Sciences, Faculty of Science, Kagoshima University, Kagoshima \\ 890-0065, Japan.E-mail: sky@sci.kagoshima-u.ac.jp
}

Table of contents

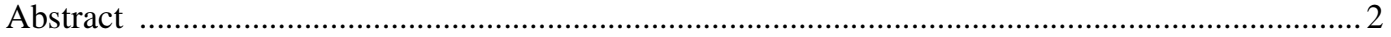

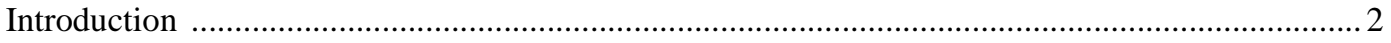

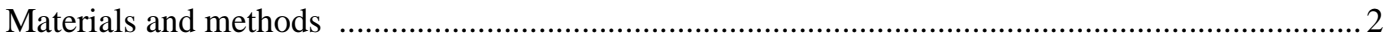

Key to Oriental Probolomyrmex species based on the worker ................................................... 4

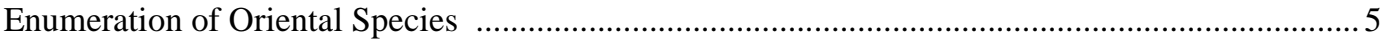

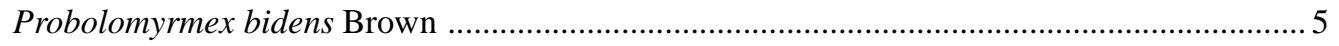

Probolomyrmex dammermani Wheeler ............................................................................. 5

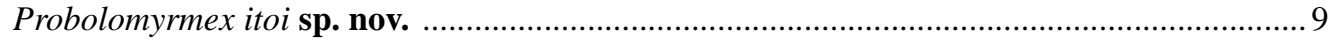

Probolomyrmex longinodus Terayama et Ogata .................................................................. 13

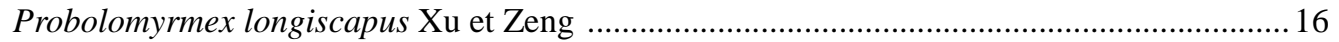

Probolomyrmex maryatiae sp. nov. ............................................................................... 26

Probolomyrmex okinawensis Terayama et Ogata ................................................................2 29

Probolomyrmex procne Brown ...............................................................................................2 29

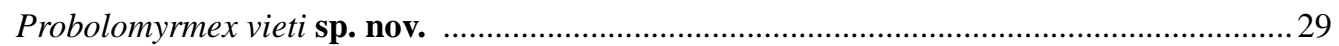

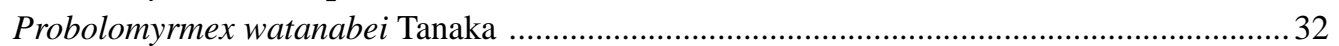

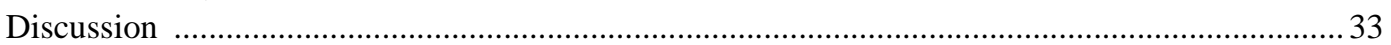

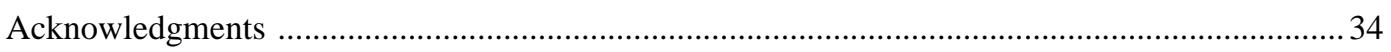

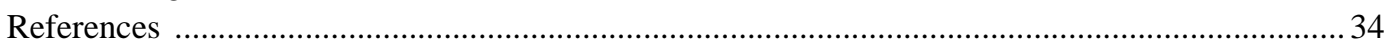




\section{Abstract}

Ten species of the proceratiine ant genus Probolomyrmex are recognized in the Oriental Region: bidens Brown, dammermani Wheeler, itoi sp. nov., longinodus Terayama et Ogata, longiscapus Xu et Zeng, maryatiae sp. nov., okinawensis Terayama et Ogata, procne Brown, vieti sp. nov. and watanabei Tanaka. The ten species and two Australian species can be classified into two species groups. The longinodus group is characterized by the petiole which is clearly longer than high, and subpetiolar process which is low with poorly developed posteroventral portion. The greavesi group is characterized by the petiole which is at most a little longer than high, and subpetiolar process which is developed and somewhat rectangular. Males of dammermani and longiscapus, and queens of dammermani, longinodus, longiscapus and watanabei were described for the first time. A key to the Oriental species of the genus is also given.

Key words: Formicidae, Probolomyrmex, Oriental, new species, male, queen, key.

\section{Introduction}

The ant genus Probolomyrmex is the only genus-rank taxon of the tribe Probolomyrmecini under the subfamily Proceratiinae (Bolton, 2003). The members of the genus share the following characteristics in the worker: body hairless but with extremely fine pubescence, micro-punctate, overlain by scattered foveolae; antennal socket located on shelf-like frontoclypeal region that overhangs the mandibles; mandible small, elongate-triangular, with acute apical tooth followed by a series of small denticles; outer surface of mandible with several thick and short setae; promesonotal suture and metanotal groove absent; abdominal tergite IV not vaulted and sternite IV not reduced (different from the members of the tribe Proceratiini) (see also Taylor, 1965; Bolton, 2003). The antenna is 12segmented in the worker and queen, and 13-segmented in the male. The mesosoma is unreduced in the queen.

The genus is circumtropical/subtropical in distribution: four species are Neotropical, three Ethiopian, two Australian, and seven Oriental (Bolton, 1995; Agosti, 1995; O'Keefe \& Agosti, 1998; Xu \& Zeng, 2000). In the course of our study on ant faunas of various areas of the Oriental Region, we have examined new material of this rare genus. In the present paper, we describe three new species, and the male and/or queen of $P$. dammermani, longinodus, longiscapus and watanabei. A key to Oriental species based on the worker is also given.

\section{Materials and methods}

Morphological terms used in the text are defined below.

Head length (HL): maximum mid-line length of head in full-face view, from median occipital border to clypeal apex. 
Head width (HW): maximum width of head in full-face view, excluding eyes (male: including eyes).

Head depth (HD): maximum depth of head in lateral view measured perpendicularly to the full-face view plane, for the male only.

Scape length (SL): maximum measurable length of scape, not including its articular boss and condyle.

Eye length (EL): maximum diameter of eye, for the queen and male only.

Cephalic index (CI): $\mathrm{HW} \times 100 / \mathrm{HL}$.

Head depth index (HDI): HW $\times 100 / H L$.

Scape index (SI): SL $\times 100 / H W$.

Eye index (EI): EL $\times 100 / \mathrm{HW}$, for the queen only.

Weber's length of mesosoma (WL): diagonal length of mesosoma in lateral view, from the anterodorsal pronotal margin to the posterior margin of propodeal lobe.

Pronotal width (PW): maximum width of pronotum viewed directly from above, for the worker and queen.

Mesoscutellar length (MstlL): maximum length of the mesoscutellum in dorsal view, from posteriormost point of the scuto-scutellar suture to posteriormost point of the mesoscutellum, for the male only.

Mesoscutellar width (MstlW): maximum width of the mesoscutellum in dorsal view, for the male only.

Dorsal petiolar width (DPtW): maximum width of petiole viewed directly from above, for the worker and queen.

Dorsal petiolar index (DPtI): DPtW $\times 100 / \mathrm{PW}$.

Mesoscutellar index (MstlI): MstlW $\times 100 /$ MstlL.

Petiole height $(\mathrm{PtH})$ : height of petiole in lateral view, measured vertically from the ventral margin of the posteroventral convexity/angle/projection of subpetiolar process to the level of the highest point of petiolar node.

Petiolar node length (PtNL): maximum length of the node, measured longitudinally from the level of the anterolateral angle/corner to that of the posteriormost extension of the petiolar tergum, where it surrounds the gastric articulation.

Lateral petiolar index (LPtI): PtNL $\times 100 / \mathrm{PtH}$.

All images of workers and queens were produced using Syncroscopy Auto-Montage Essentials version 5.02 from a series of photographs on different focal planes which were taken with Nikon Coolpix 8400 attached to Nikon Eclipse E600 or Nikon SMZ1000. Noises (ghost images) and unnecessary parts (unfocused appendages, insect pin, etc.) surrounding objects were erased and cleaned up using Adobe Photoshop CS2. Observations of males were carried out under scanning electron microscope (JEOL JSM5600LV), where the specimens were sputter-coated with gold. Images of wings were taken with Coolpix 5400 attached to Olympus SZX12 and male genitalia with Nikon Coolpix 8400 attached to Nikon Eclipse E600. 
Abbreviations of the specimen depositories are: MZB, Museum Zoologicum Bogoriense, Bogor, Indonesia; IEBR, Entomological collection of the Institute of Ecology and Biological Resources, Vietnam; ITBC, Entomological collection of the Institute for Tropical Biology and Conservation, Universiti Malaysia Sabah, Malaysia; MCZC, Museum of Comparative Zoology, Harvard University, Cambridge, Massachusetts, USA; MHNG, Muséum d'Histoire Naturelle, Geneva, Switzerland; ACEG, ant collection managed by Katsuyuki Eguchi; SKYC, ant collection managed by Seiki Yamane. Abbreviations of collectors are: Eg, Katsuyuki Eguchi; FI, Fuminori Ito (Kagawa Univ., Japan); SKY, Seiki Yamane.

\section{Key to Oriental Probolomyrmex species based on the worker}

1. Petiole posterodorsally with a pair of strong angles/teeth (in dorsal or lateral view)...2

- Petiole posterodorsally without a pair of strong angles/teeth; posterodorsal margin at most weakly emarginated medially 3

2. Petiole (including subpetiolar process) as long as high; subpetiolar process developed, subrectangular bidens Brown

- Petiole (including subpetiolar process) distinctly longer than high; subpetiolar process low, with a small anteroventral projection procne Brown

3. Posterodorsal margin of petiole in dorsal view well produced medially into a horn (Fig. 8D) watanabei Tanaka

- Posterodorsal margin of petiole in dorsal view not produced (Figs. 1D, 6D, 7D), or produced but truncate or shallowly emarginate medially (Figs. 2D, 3D, 4D, 5D) ....... 4

4. Posteroventral portion of subpetiolar process spinose, protruding or sharply angled (Figs. 5C, 7C).

- Posteroventral portion of subpetiolar process rounded or obtusely angled (Figs. 1C, 2C, 3C, 4C, 6C)

5. Petiole in profile with its posterior outline straight and vertical (above the articulation with gaster); anteroventral projection of subpetiolar process relatively thin and translucent (Fig. 7C) vieti sp. nov.

- Petiole in profile with its posterior outline concave (above the articulation with gaster); anteroventral projection of subpetiolar process relatively thick and not translucent (Fig. 5C) maryatiae sp. nov.

6. Anteroventral portion of subpetiolar process in profile broadly expanded anteroventrad (Fig. 6C) okinawensis Terayama et Ogata

- Anteroventral portion of subpetiolar process in profile narrowly expanded anteriad or

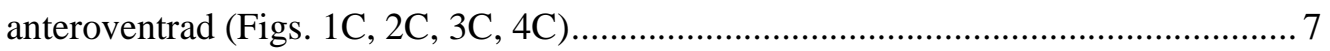

7. Petiolar node in profile with an extremely long and flattened dorsal outline (Fig. 2C); SI> 160 itoi sp. nov.

- Petiolar node in profile with a dorsal outline which is moderately long (or short) and 
flattened or curved (Figs. 1C, 3C, 4C); SI $<150$

8. Posterior face of propodeum margined laterally with a carina which is angulate dorsally but only rarely forms a conspicuous propodeal spine (1C); LPtI $<135$

dammermani Wheeler

- Posterior face of propodeum margined laterally with a carina which forms a triangular propodeal spine (Figs. 3C, 4C); LPtI $>135$

9. Frontal carina in profile lower, with a semicircular outline (Fig. 9C); $4^{\text {th }}$ antennal segment a little shorter than broad (Fig. 10C) longinodus Terayama et Ogata

- Frontal carina in profile higher, with a gently triangular outline (Fig. 9D); $4^{\text {th }}$ antennal segment a little longer than broad (Fig. 10D) longiscapus $\mathrm{Xu}$ et Zeng

\section{Enumeration of Oriental Species}

\section{Probolomyrmex bidens Brown}

Probolomyrmex bidens Brown, 1975: 56, figs. 7, 9. Holotype: worker, Palni Hills, $2150 \mathrm{~m}$ alt., 10 km NW of Kodaikanal, Madras State, India, 15/ix/1972, Besuchet, Löbi \& Mussard (MHNG) [not examined].

Recognition. This species is similar to $P$. maryatiae sp. nov. and $P$. vieti sp. nov., but is well distinguished from the latter by the petiolar node posterodorsally with paired teeth in the worker. Sexual forms of this species are unknown.

Distribution. Known only from the type locality.

\section{Probolomyrmex dammermani Wheeler}

(Figs. 1A-F, 9A, 10A, 11A-E, 15A, B, 16A-C)

Probolomyrmex dammermani Wheeler, 1928: 7-9, fig. 1. [Taylor, 1965: 356-358, figs. 17-19 (revision of the genus); Ito et al., 2001: 403 (species list).] Syntypes: 4 workers, Buitenzorg [Bogor], Java, Indonesia, 18/xii/1922, K. Dammerman (MCZC) [one worker examined].

Nontype material examined. VIETNAM: Nghe An: Sang Le Forest, Tuong Duong [colony: Eg01iv06-08]; INDONESIA: W. Java: Kebun Raya Bogor [general coll.: FI, Jan/ 1993; colony: FI95-517 (including queen \& male), FI95-558 , FI95-591 (including male), FI95-717 (including queen \& male), FI97-45, JV04-SKY-12 (including queen)], Peucang Isl., Ujung Kulon N. P. [colony: Fl97-117], Pasir Pugog, Pangandaran N. P. [colony: Eg12v06-16]; C. Java: Kuwalahan (plantation at $800 \mathrm{~m}$ alt.) [general coll.: E. Kaufmann $e t$ al.: No. 74, 3/xii/2000]; W. Bali: Sumber Lampok, Geroka, Buleleng, Bali Barat N. P. [colony: Eg26v06-04 (including queen)], Dusun PK Jelati, Mendaya [general coll.: SKY, 5-6/v/1998]; PHILIPPINES: Negros Or.: Chapman's Gard., Valencia, Dumaguete [general coll.: V. Samarita, 29/xii/1998]. 


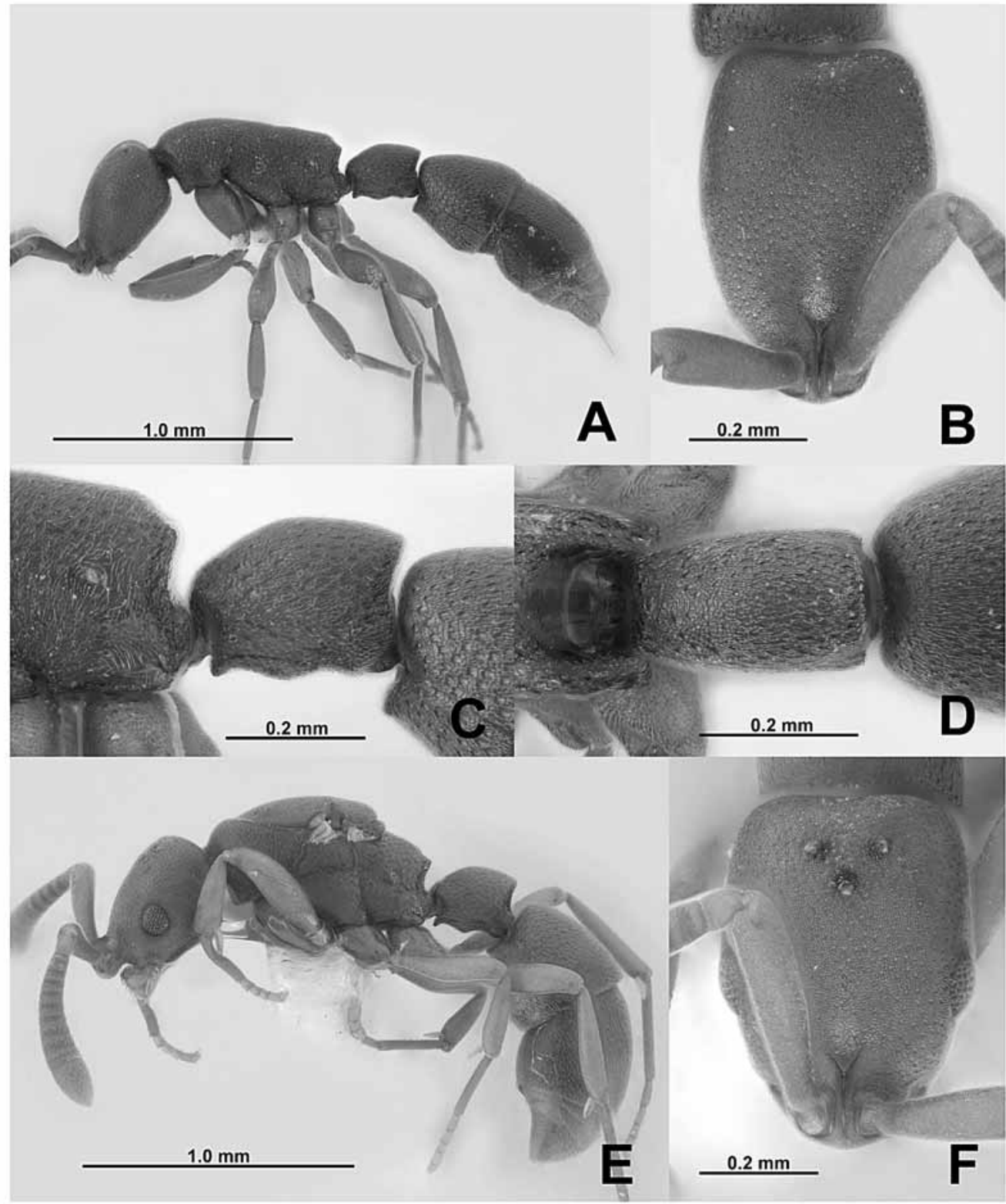

FIGURE 1. Probolomyrmex dammermani Wheeler. A-D, worker (JV04-SKY-12); E, F, queen (FI95-717). A, E, body in profile; B, F, head in full-face view; C, petiole in profile; D, petiole in dorsal view.

Worker. HL, 0.54-0.66 mm; HW, 0.35-0.42 mm; SL, 0.31-0.49 mm; CI, 63-67; SI, 89-117; WL, 0.69-0.96 mm; PW, 0.26-0.34 mm; DPtW, 0.15-0.19 mm; DPtI, 55-59; PtH, 0.21-0.26 mm; PtNL, 0.23-0.34 mm; LPtI, 110-131 (N=7). 


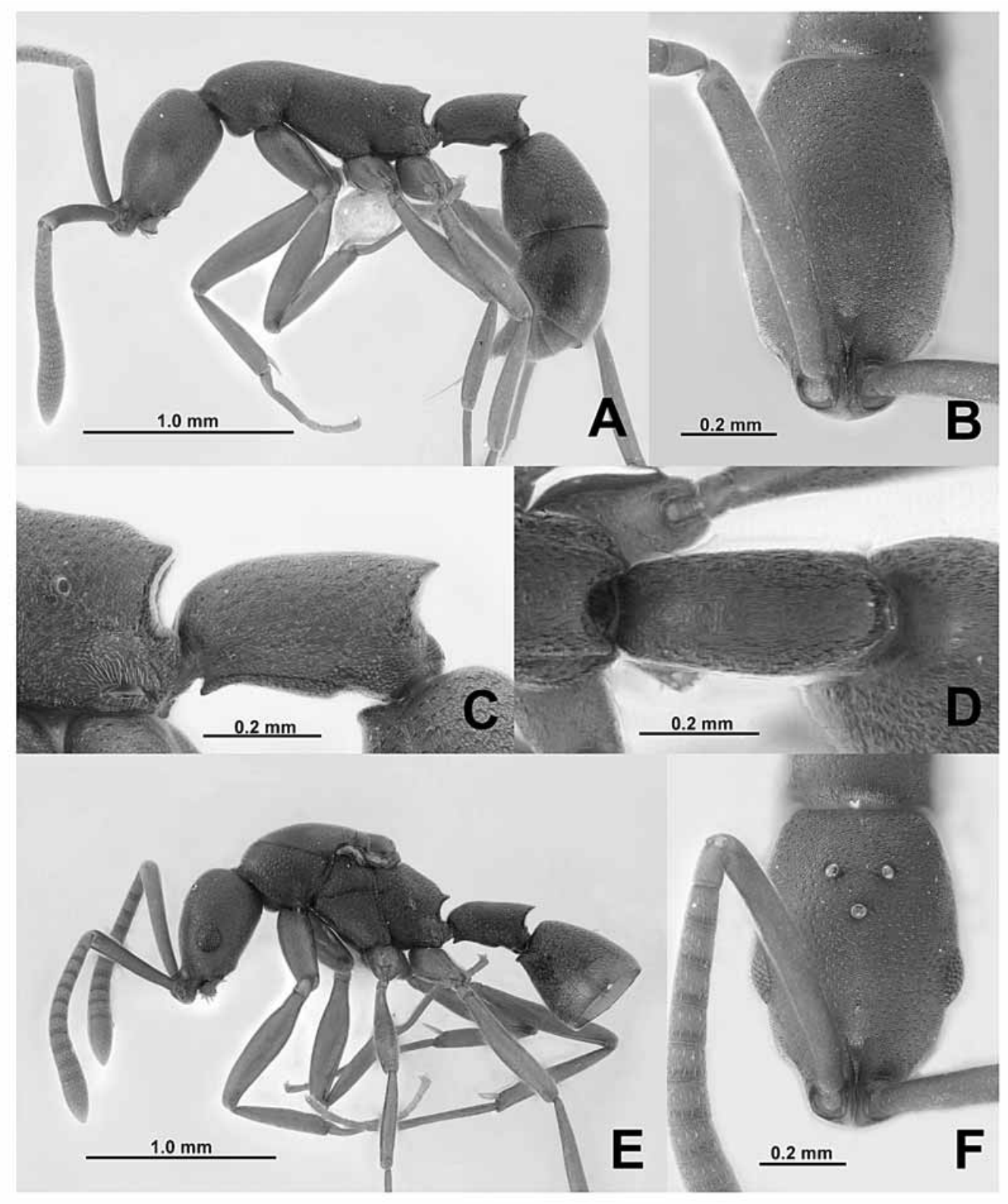

FIGURE 2. Probolomyrmex itoi sp. nov. A-D, worker (type series); E, F, queen (type series). $\mathrm{A}, \mathrm{E}$, body in profile; $\mathrm{B}, \mathrm{F}$, head in full-face view; $\mathrm{C}$, petiole in profile; $\mathrm{D}$, petiole in dorsal view.

Queen (alate and dealate queens). HL, 0.61-0.66 mm; HW, 0.42-0.44 mm; SL, 0.40-0.49 mm; EL, 0.11-0.13 mm; CI, 67-70; SI, 93-111; EI, 26-30; WL, 0.91-1.02 mm; PW, 0.37-0.38 mm; DPtW, 0.20 mm; DPtI, 53-54; PtH, 0.26-0.28 mm; PtNL, 0.30-0.33 mm; LPtI, 115-127 (N=3, but $\mathrm{N}=2$ for DPtW and DPtI). Body ferruginous brown. Head in full-face view elongate, with very weakly convex sides and almost straight occipital 
border. Eye a little shorter than the width of apical antennal segment. Antennal scape when laid backward reaching or a little extending beyond the level of posterior margin of median ocellus; relative lengths of antennal segments II-XII as in the worker (see Fig. 10A); segment III almost as long as IV. Pronotum large; mesoscutum ca. 1.1-1.2 times as long as broad, in profile weakly convex; notauli absent; parapsidal lines very fine; scutoscutellar suture fine, very weakly and roundly curved posteriad; scutellum in profile with relatively steep posterior slope; axilla poorly separated from scutellum by an obscure impression but not by a suture; mesopleuron (except in its posteriormost part) well divided by a suture into anepisternum and katepisternum; raised median area of metanotum with gentle lateral slopes; suture between metepisternum and propodeum absent; a weak depression present dividing metepisternum into anepisternum and katepisternum; orifice of metapleural gland small, opening posterolaterad; posterior margin of propodeal dorsum in dorsal view moderately and broadly concave; posterior face of propodeum margined laterally with a well-developed translucent lamella which in profile forms an angle in upper portion. Petiole including subpetiolar process longer than high, in profile with very weakly concave posterior outline (above the articulation with gaster), in dorsal view gradually widened toward the midlength and parallel-sided in posterior half; posterodorsal margin of petiolar node in dorsal view almost straight or very weakly convex; subpetiolar process low, with an acute anterior projection and posteriorly with a low and sometimes obtusely angulate prominence. Abdominal segment III (gastral segment I) in profile relatively short, gently narrowed anteriad in the anterior 3/4 (in the queen from Bali the segment in profile a little slenderer). Wing structure and venation as in the male. Hind wing with three hamuli.

Male. HL, 0.46-0.47 mm; HW, 0.46-0.47 mm; CI, 98-102; HD, 0.38-0.41 mm; HDI, 83-87; EL, 0.23-0.24 mm; SL, 0.30-0.32 mm; SI, 64-68; MstlL, 0.20-0.22 mm; MstlW, 0.20-0.23 mm; MstlI, 95-110; WL, $0.95 \mathrm{~mm}$; PtNL, 0.28-0.32 mm; PtH, 0.16-0.20 mm; LPtI, $155-175(\mathrm{~N}=3$ but $\mathrm{N}=1$ for $\mathrm{WL})$. Head in lateral view relatively thin $(\mathrm{HDI}<90)$; protrusion of the frontoclypeal region relatively long, so that antennal insertion situated in the middle of its dorsal surface. Frontal carina low, not or slightly exceeding posterior margin of antennal insertions in full-face view. Eye relatively narrow, weakly widened ventrally. Antennal flagellum relatively long, filiform, with antennal segment III distinctly longer than segment II; segment XI (the third from apex) distinctly longer than broad; ventrolateral surface of the apical segment not concave. Mandible elongated triangular, with only a single strong apical tooth on its masticatory margin; basal angle distinct. Palpal formula: maxillary 4, labial 2; maxillary palp moderately long; the third palpomere distinctly longer than the second, and the apical distinctly longer than the third. With the mesosoma in lateral view, pronotum distinctly higher than mesoscutum; metanotum strongly produced posteriorly, and a suture separating it from mesoscutellum strongly notched; anepisternum of metapleuron separated from metakatepisternum and propodeum by a deep furrow; a suture between metakatepisternum and propodeum weak, but 
separation between the plates recognizable; dorsal margin of propodeum forming an angle with posterior slope. With the mesosoma in dorsal view, mesonotum lacking notauli; parapsidal lines distinct; axillae distinct; mesoscutellum slightly broader than long; declivitous face of the propodeum very slightly concave with weak, obtuse lateral lamellae. Petiole in lateral view without a distinct peduncle; node long with gentle anterior slope and steep posterior slope; posterodorsal margin angular; subpetiolar process narrowly developed with its apex sharp. Abdominal sternum IX long, with its apical margin gently pointed medially. Genitalia retractile. With the phallus in lateral view, the basal ring moderately long and its dorsal margin gently declined; dorsal margin of the basiparamere gently raised in its basal portion; posterodorsal slope gentle; digitus volsellaris simply curved ventrally in its apical portion; penis valve relatively thick and nearly straight, not strongly narrowed apically, and its apical portion blunt and slightly curved ventrally. Paramere thin; its expanded inner faces directed ventrally, of which apical portion is curved dorsally. Aedeagal apodeme relatively narrow. On fore wing, costa and radius apical to stigma vestigial; Rsf 2 and Rsf3 completely absent; radial sector never reaching costal margin; Mf1, Rs+M and media apical to Rs+M present; cu-a cross vein present. On hind wing, Rsf4+5 present; jugal lobe absent.

Recognition. The nontype workers agree with the syntype worker. However, a certain variation is seen in the following characters: punctation on the body surface; convexity of lateral outlines of head in full-face view; concavity of occipital border (also mentioned by Taylor, 1965); development of posterior portion of subpetiolar process (also mentioned by Taylor, 1965); and development of posterolateral lamella of propodeum (sometimes forming a triangular propodeal spine). The flagellum is more slender in the worker and queen from Bali than in those from the other localities. Workers from colony Eg01iv06-08 are smaller, antennal scape shorter, and petiole in profile shorter $(\mathrm{N}=2$; WL $0.69-0.73 \mathrm{~mm}$, SI 89, LPtI 110) than in the material from the other localities (N=5; WL 0.88-0.96 mm, SI 103-117, LPtI 116-131).

In the worker this species is most similar to P. longinodus, but well distinguished from the latter by the relatively shorter petiole (LPtI < 135) and poorly developed propodeal teeth in the worker (see also Terayama \& Ogata, 1988). In the male, P. dammermani is similar to $P$. longiscapus and $P$. longinodus, but the former can be separated from the latter two by the following characters: 1) thinner head in lateral view, 2) lower frontal carina, 3) narrower eye, and 4) narrower abdominal sternum IX and genitalia.

Distribution. Known from M. Vietnam, Java and Bali (Indonesia), and Negros (Philippines).

\section{Probolomyrmex itoi sp. nov.}

(Figs. 2A-F, 9B, 10B)

Type material. Holotype: worker belonging to colony FI92-153, Sitiung, W. Sumatra, 
Indonesia, 7/i/1992, FI (MZB). Paratypes: 3 workers and a queen from the same colony to which the holotype belongs (MCZC, MHNG, SKYC).

Nontype material examined. MALAYSIA: Sarawak: Lambir N. P., Miri [general coll.: Eg, 23/vi/1998]. INDONESIA: W. Sumatra: Ulu Gadut, Padang [FI97-510]. Eguchi's informal species code "Probolomyrmex sp. eg-5" and Yamane's "Probolomyrmex sp. 2" apply to this species.

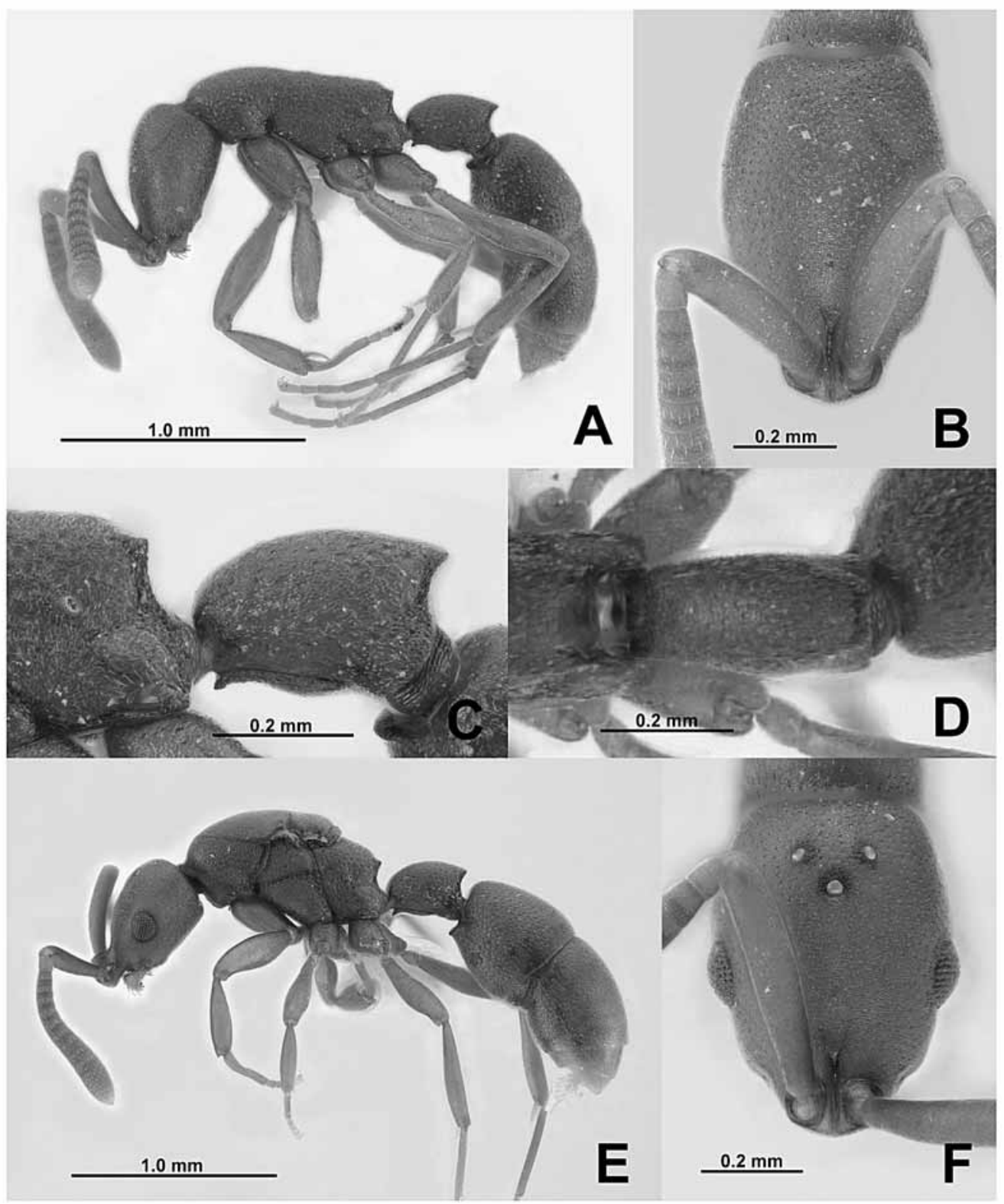

FIGURE 3. Probolomyrmex longinodus Terayama et Ogata. A-D, worker (holotype); E, F, queen (TK15i04-01). A, E, body in profile; B, F, head in full-face view; C, petiole in profile; D, petiole in dorsal view. 


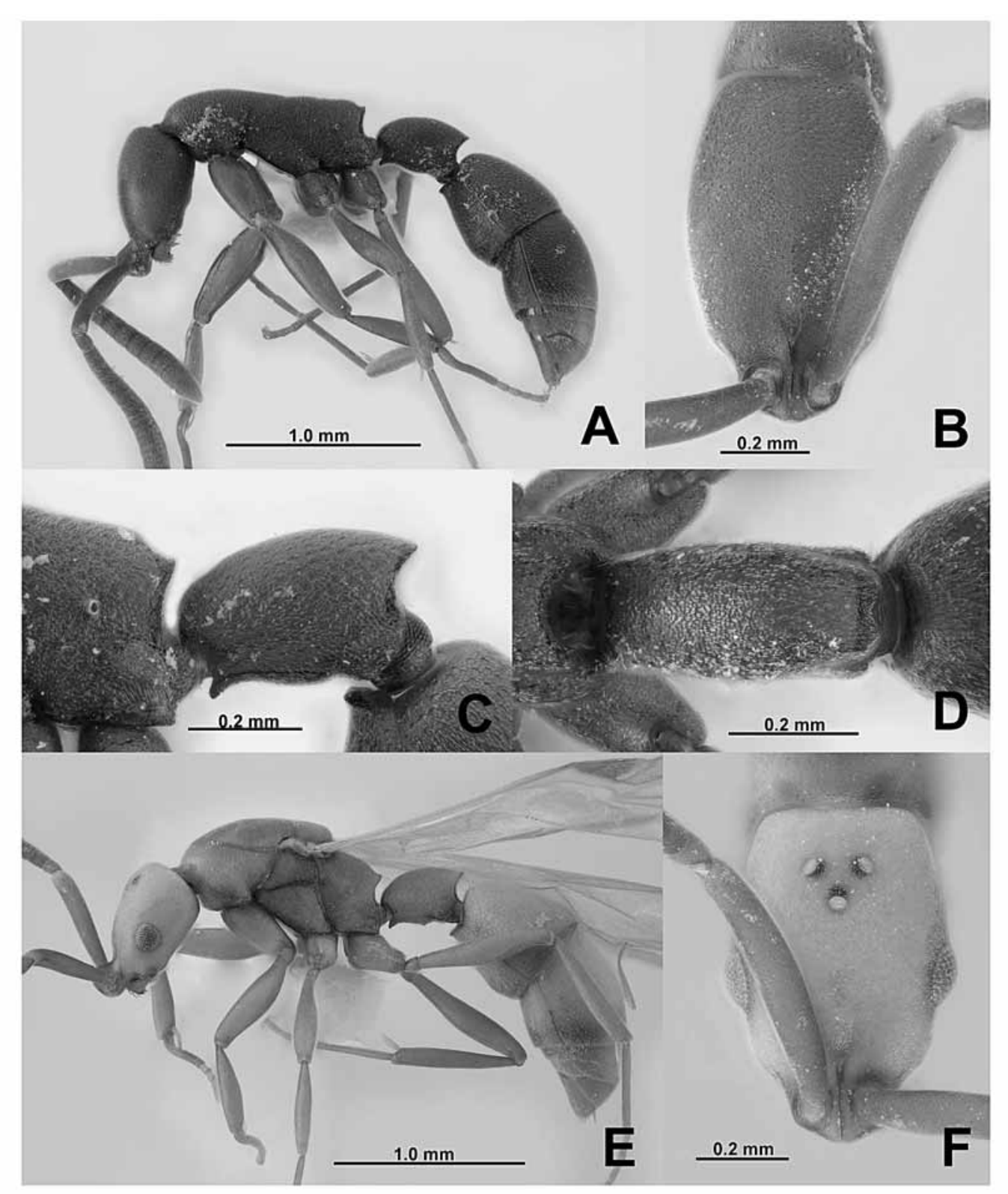

FIGURE 4. Probolomyrmex longiscapus Xu et Zeng. A-D, worker (Eg09vi05-18); E, F, queen (Eg09vi05-18). A, E, body in profile; B, F, head in full-face view; C, petiole in profile; D, petiole in dorsal view.

Worker. HL, 0.76-0.80 mm; HW, 0.42-0.48 mm; SL, 0.76-0.81 mm; CI, 55-60; SI, 165-186; WL, 1.18-1.30 mm; PW, 0.38-0.41 mm; DPtW, 0.19-0.22 mm; DPtI, 50-54; PtH, 0.23-0.28 mm; PtNL, 0.41-0.47 mm; LPtI, 168-178 (N=5). Body ferruginous brown; area where eye is located in the queen pale colored; mandible entirely yellow; legs paler; apical gastral segments yellowish. Head in full-face view extremely elongate, with 
weakly convex sides; occipital border almost straight or very shallowly concave. Eye absent. Antennal scape when laid backward slightly extending beyond occipital border; relative lengths of antennal segments II-XII as in Fig. 10B; segment III as long as or a little longer than IV. Promesonotum in profile very weakly convex; posterior margin of propodeal dorsum in dorsal view deeply concave; posterior face of propodeum margined laterally with a carina which forms a triangular propodeal spine at upper portion. Petiole including subpetiolar process much longer than high, in profile with weakly concave posterior outline (above the articulation with gaster); posterodorsal margin of petiolar node in dorsal view almost straight or with a shallow median emargination; subpetiolar process inconspicuous, only with an acute anterior projection. Abdominal segment III (gastral segment I) in profile slender, gently narrowed anteriad in the anterior 3/4).

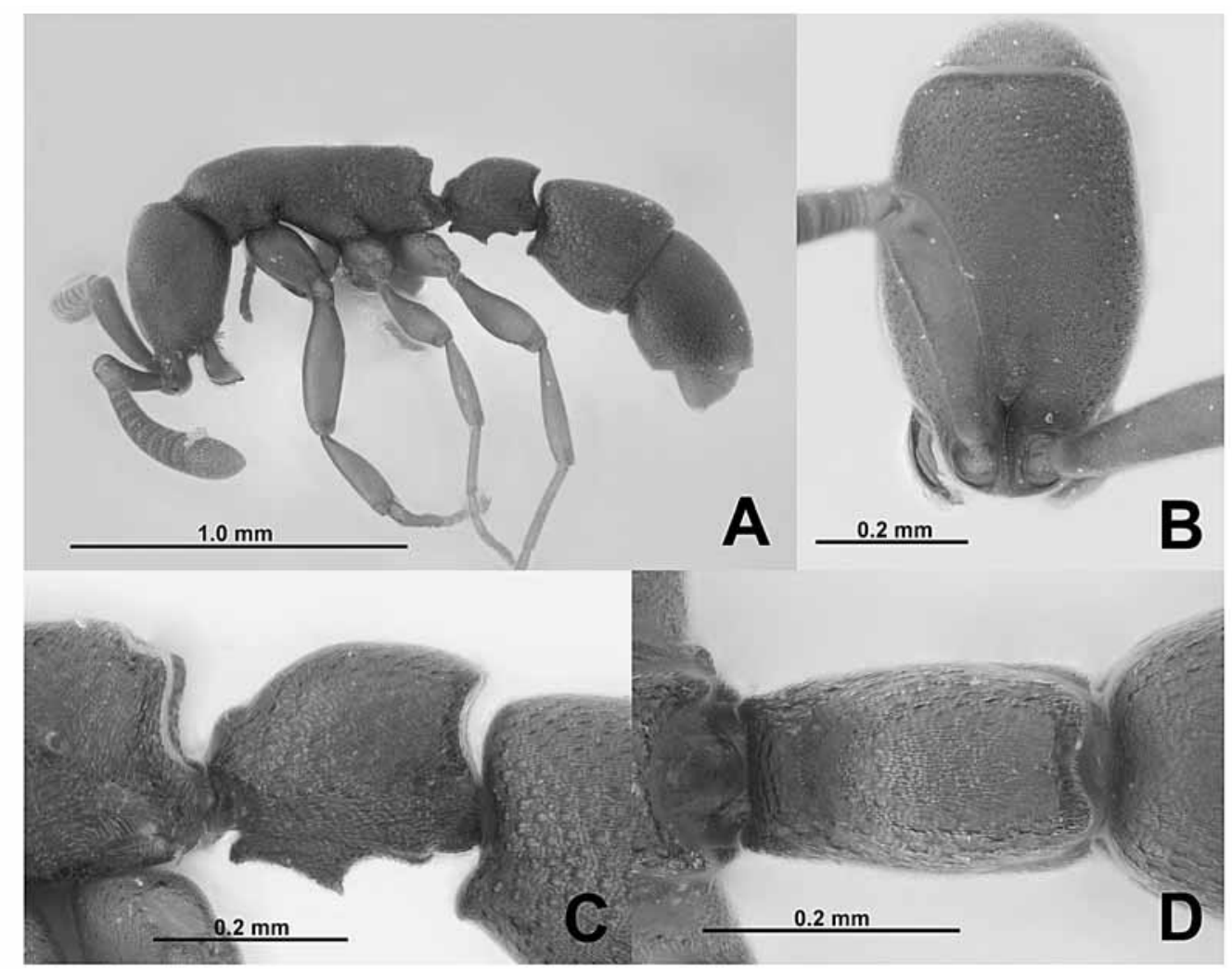

FIGURE 5. Probolomyrmex maryatiae sp. nov. A-D, worker (type series). A, body in profile; B, head in full-face view; $\mathrm{C}$, petiole in profile; D, petiole in dorsal view.

Queen (dealate queen). HL, $0.75 \mathrm{~mm}$; HW, $0.47 \mathrm{~mm}$; SL, $0.74 \mathrm{~mm}$; EL, $0.15 \mathrm{~mm}$; CI, 63; SI, 157; EI, 32; WL, 1.23 mm; PW, 0.43 mm; DPtW, 0.19 mm; DPtI, 44; PtH, 0.25 $\mathrm{mm}$; PtNL, $0.44 \mathrm{~mm}$; LPtI, $176(\mathrm{~N}=1)$. Body ferruginous brown; antennae and legs paler. Head in full-face view elongate, with weakly convex sides and almost straight occipital border. Eye slightly longer than the width of apical antennal segment. Antennal scape 
when laid backward extending beyond the level of posterior margin of lateral ocelli and nearly reaching occipital border; relative lengths of antennal segments II-XII as in the worker; segment III a little longer than IV. Pronotum large; mesoscutum ca. 1.3 times as long as broad, in profile very weakly convex; notauli absent; parapsidal lines fine but distinct; scuto-scutellar suture fine, very weakly and roundly curved posteriad; scutellum in profile with steep posterior slope; axilla poorly separated from scutellum by an obscure impression but not by a suture; mesopleuron (except in its posteriormost part) well divided by a suture into anepisternum and katepisternum; raised median area of metanotum with gentle lateral slopes; suture between metepisternum and propodeum absent; a deep depression present dividing metepisternum into anepisternum and katepisternum; orifice of metapleural gland small, opening posteriad; posterior margin of propodeal dorsum in dorsal view deeply concave; posterior face of propodeum margined laterally with a lamella which forms a triangular propodeal spine at upper portion; outline from propodeal spine to propodeal lobe in profile weakly concave. Petiole including subpetiolar process much longer than high, in profile with a extremely long, flattened dorsal outline and weakly concave posterior outline (above the articulation with gaster), in dorsal view gradually widened toward the midlength and parallel-sided in posterior half; posterodorsal margin of petiolar node in dorsal view truncated medially; subpetiolar process inconspicuous, only with an acute anterior projection. Abdominal segment III (gastral segment I) in profile slender, relatively gently narrowed anteriad in the anterior 4/5; abdominal sternum III in profile only weakly convex in front of its posterior end.

Recognition. This species is similar to P. longiscapus Xu et Zeng, but SI and LPtI are much greater in the worker and queen of $P$. itoi than in those of $P$. longiscapus.

Distribution. Known only from Borneo and Sumatra.

\section{Probolomyrmex longinodus Terayama et Ogata}

(Figs. 3A-F, 9C, 10C, 12A-E, 15C, D, 16D-F)

Probolomyrmex longinodus Terayama et Ogata, 1988: 592-594, figs. 6-8. Holotype: worker, Yonehara, Ishigaki Is., Ryukyus, Japan, 15/iii/1984, Y. Fukumoto (Faculty of Agriculture, Kyushu Univ., Japan) [examined].

Nontype material examined. JAPAN: S. Ryukyus: Yonaguni-jima [T. Kikuchi's colony: TK15i04-01, -02, -04, -05 (all of these colonies including the queen)]. TAIWAN: Nantou: Puli [K. Onoyama, 21/viii/1995: in Ant Collection of Masashi Yoshimura (MY945: including the male and queen)]; Kaohsiung: Liukuei [M. Terayama, 17/viii/1987 (including the male and queen)]. THAILAND: Chiang Mai: Doi Suthep (1500 m alt.) [M. Terayama \& S. Kubota, 18/viii/1992].

Worker. HL, 0.65-0.75 mm; HW, 0.43-0.49 mm; SL, 0.50-0.62 mm; CI, 64-70; SI, 111-127; WL, 0.95-1.16 mm; PW, 0.33-0.40 mm; DPtW 0.18-0.23 mm; DPtI, 50-58; PtH, 0.23-0.30 mm; PtNL, 0.33-0.41 mm; LPtI, 137-148 (N=10). 


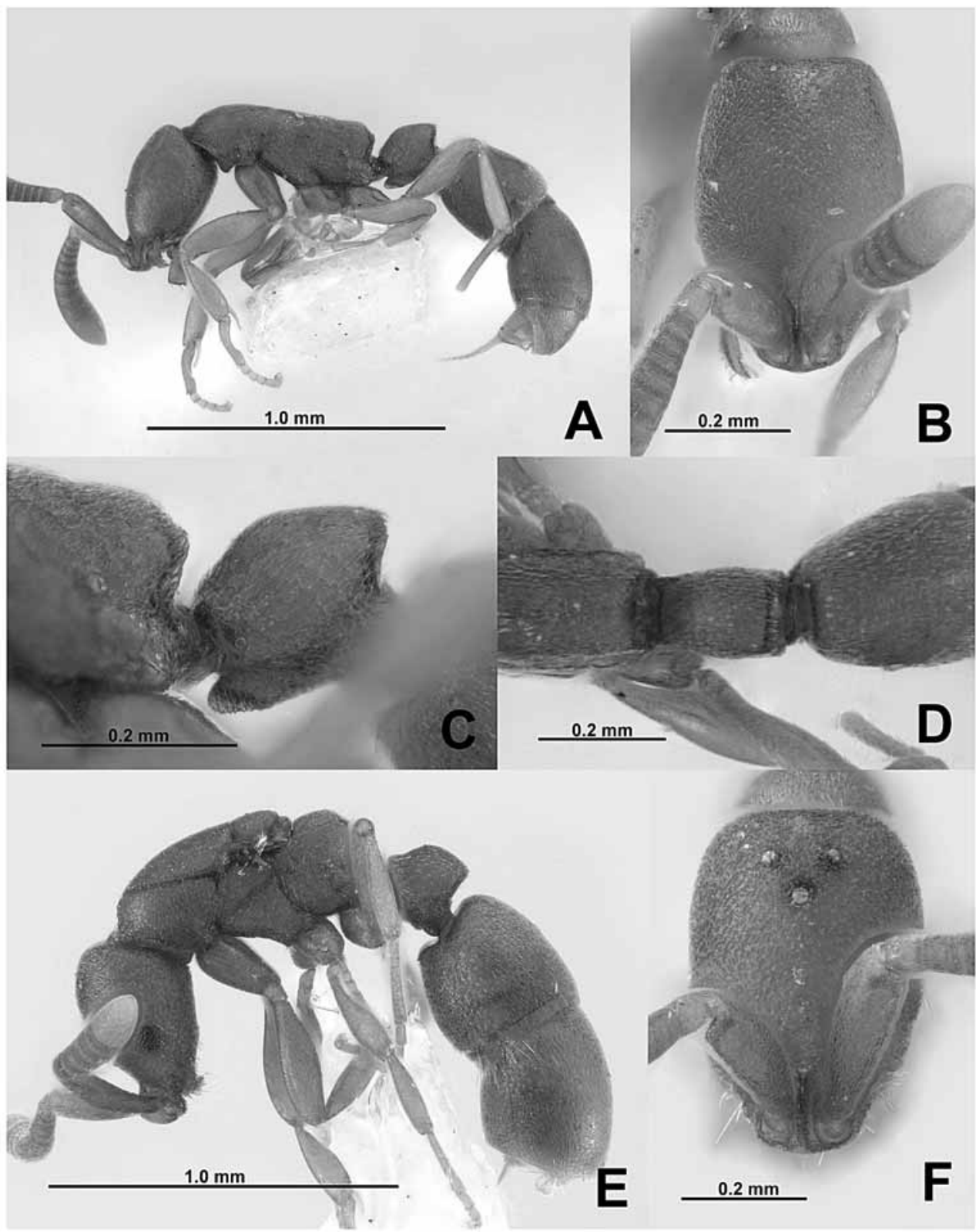

FIGURE 6. Probolomyrmex okinawensis Terayama et Ogata. A-D, worker (holotype); E, F, queen (paratype from Nakijin-jyoushi, Okinawa-hontou). A, E, body in profile; B, F, head in full-face view; $\mathrm{C}$, petiole in profile; $\mathrm{D}$, petiole in dorsal view.

Queen. HL, 0.68-0.70 mm; HW, 0.47-0.48 mm; SL, 0.52-0.58 mm; EL, 0.13-0.15 mm; CI, 68-71; SI, 108-121; EI, 27-31; WL, 1.06-1.12 mm; PW, 0.39-0.44 mm; DPtW 0.20-0.23 mm; DPtI, 49-54; PtH, 0.27-0.29 mm; PtNL, 0.36-0.38 mm; LPtI, 128-141 $(\mathrm{N}=7)$. Body ferruginous brown. Head in full-face view elongate, with weakly convex sides and almost straight occipital border. Frontal carina in profile relatively low as in the 
worker (see Fig. 9C). Eye as long as or a little longer than the width of apical antennal segment. Antennal scape when laid backward reaching or extending beyond the level of anterior margin of lateral ocelli; relative lengths of antennal segments II-XII as in the worker (see Fig. 10C); segment III a little longer than IV; IV a little shorter than broad. Pronotum large; mesoscutum 1.2-1.3 times as long as broad, in profile very weakly convex; notauli absent; parapsidal lines very fine or sometimes invisible; scuto-scutellar suture fine, very weakly and roundly curved posteriad; scutellum in profile with relatively gentle posterior slope; axilla poorly separated from scutellum by an obscure impression but not by a suture; mesopleuron (except in its posteriormost part) well divided by a suture into anepisternum and katepisternum; raised median portion of metanotum with gentle lateral slopes; suture between metepisternum and propodeum absent; a deep depression present dividing metepisternum into anepisternum and katepisternum; orifice of metapleural gland small, opening posterolaterad; posterior margin of dorsum of propodeum in dorsal view widely and moderately concave; posterior face of propodeum margined laterally with a carina which forms a triangular propodeal spine; outline from propodeal spine to propodeal lobe in profile weakly concave. Petiole including subpetiolar process much longer than high, in profile with weakly concave posterior outline (above the articulation with gaster), in dorsal view gently widened toward its midlength, and then parallel-sided or slightly constricted in front of the posterior margin; posterodorsal margin of petiolar node in dorsal view with a very shallow median emargination/concavity; subpetiolar process inconspicuous, only with an acute anterior projection. Abdominal segment III (gastral segment I) in profile relatively short, gently narrowed anteriad in the anterior 3/4. Wing structure and venation as in the male. Hind wing with three hamuli.

Male. HL, 0.47-0.55 mm; HW, 0.54-0.59 mm; CI, 107-117; HD, 0.48-0.53 mm; HDI, 91-104; EL, 0.26-0.30 mm; SL, 0.34-0.42 mm; SI, 63-71; MstlL, 0.19-0.22 mm; MstlW, 0.23-0.28 mm; MstlI, 121-140; WL, $1.08 \mathrm{~mm}$; PtNL, 0.31-0.39 mm; PtH, 0.24-0.28 mm; LPtI, 129-158 ( $\mathrm{N}=4$, but $\mathrm{N}=3$ for HD and HDI, $\mathrm{N}=1$ for WL). Head in lateral view relatively thick (HDI>90); protrusion of frontoclypeal region relatively long so that antennal insertion is situated in the middle of its dorsal surface. Frontal carina high, distinctly exceeding posterior margin of antennal insertions in full-face view. Eye relatively broad, strongly widened ventrally. Antennal flagellum relatively long, filiform; antennal segment III distinctly longer than segment II; segment XI (the third from apex) distinctly longer than broad; ventrolateral surface of the apical segment not concave. Mandible triangular, with four small dents and a single strong apical tooth on its masticatory margin; its basal angle not strongly angular but distinct. Palpal formula: maxillary 4, labial 2; maxillary palp relatively long; the second palpomere distinctly longer than the third, and the apical distinctly longer than the third. Pronotum distinctly higher than mesoscutum in lateral view; metanotum strongly produced posteriorly, and a suture separating it from mesoscutellum strongly notched; anepisternum of metapleuron separated from metakatepisternum and propodeum by a deep furrow; a suture between 
metakatepisternum and propodeum weak, but recognizable; dorsal margin of propodeum forming a weak angle with the posterior slope. With the mesosoma in dorsal view, mesonotum lacking notauli; parapsidal lines distinct; axillae distinct; mesoscutellum slightly broader than long; declivitous face of the propodeum very slightly convex with weak, obtuse posterolateral lamellae. Petiole without a distinct peduncle; petiolar node long, with gentle anterior and posterior slopes; posterodorsal margin not angular but rounded; subpetiolar process narrowly developed with its apex sharp. Abdominal sternum IX long; its apical margin gently pointed medially. Genitalia retractile. With the phallus in lateral view, the basal ring relatively short and its dorsal margin steeply declined; basiparamere with the dorsal margin suddenly raised in its basal portion and posterodorsal margin angular; digitus volsellaris somewhat steeply curved ventrally on its apical portion; penis valve distinctly narrowed apically, and its apical portion relatively sharp and not curved ventrally. Paramere thin; its expanded inner faces directed ventrally, with the apical portion very slightly curved dorsally. Aedeagal apodeme relatively wide. On fore wing, costa and radius apical to stigma vestigial; Rsf 2 and Rsf 3 completely absent; radial sector never reaching costal margin; Mf1, Rs+M and media apical to Rs+M present; cu-a cross vein present. On hind wing, Rsf4+5 present; jugal lobe absent.

Recognition. P. longinodus is most similar to P. longiscapus Xu et Zeng. Xu \& Zeng (2000) gave the following diagnostic characteristics by which the latter is separated from the former in the worker: head longer, occipital margin almost straight; scape much longer; propodeal teeth larger; and in dorsal view posterior $1 / 3$ of petiolar node narrowed backward. But when the additional nontype material was included in our examination, the two species were not separated by CI, condition of occipital margin, size of propodeal teeth, and shape of petiolar node. Although SI in the worker seems to be a valuable character separating the two species, the Taiwanese form has larger SI (122-127, 3 workers measured). In the present study we found only a small difference between the workers of the two species (as given in the key), while the male provides better characters which support the separation of the two species (see under P. longiscapus).

Anterior slope of petiole is gentler, posterior portion of subpetiolar process is slightly higher, and mesosoma in dorsal view is a little slenderer in the workers from Thailand than in those from the S. Ryukyus. However, there is almost no difference in SI between them.

Distribution. S. Ryukyus, Taiwan, N. Thailand.

\section{Probolomyrmex longiscapus Xu et Zeng}

(Figs. 4A-F, 9D, 10D, 13A-E, 15E, F, 16G-I)

Probolomyrmex longiscapus Xu et Zeng, 2000: 214-216, figs. 9-11. Holotype: worker, Nanqian Village, Mengla County, Yunnan Province, China, 11/iii/1998, G. Zeng (Southwest Forestry College, Yunnan, China) [not examined]. Paratype: 1 worker with same data as the holotype (Southwest Forestry College) [not examined]. 
Nontype material examined. VIETNAM: Ninh Vinh: Cuc Phuong N. P. [colony: Eg09vi05-18 (including queen \& male)].

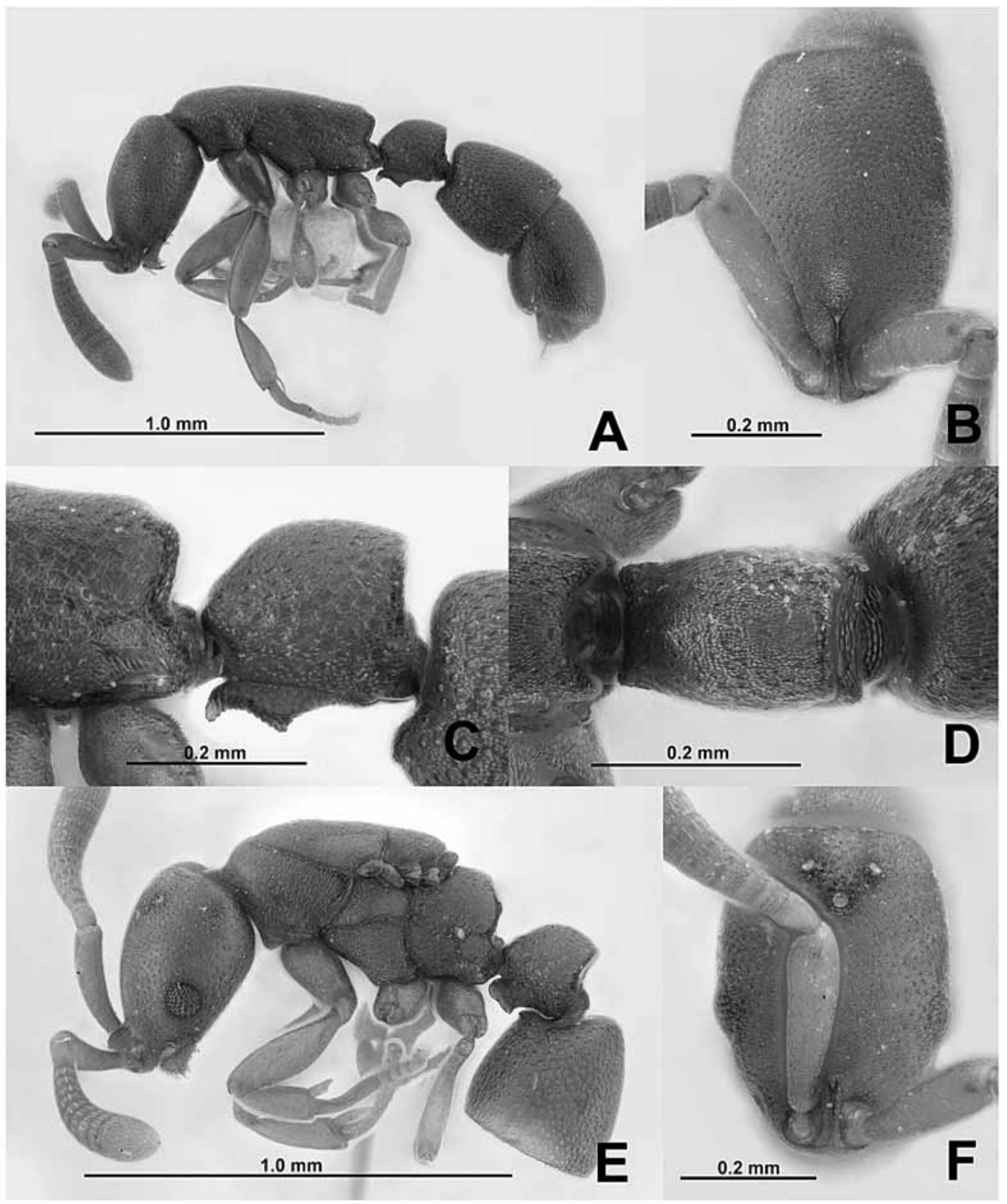

FIGURE 7. Probolomyrmex vieti sp. nov. A-D, worker (type series); E, F, queen (FI93-60). A, E, body in profile; $\mathrm{B}, \mathrm{F}$, head in full-face view; $\mathrm{C}$, petiole in profile; $\mathrm{D}$, petiole in dorsal view.

Worker. HL, 0.77-0.79 mm; HW, 0.47-0.48 mm; SL, 0.67-0.69 mm; CI, 61-62; SI, 142-147; WL, 1.13-1.18 mm; PW, 0.39-0.40 mm; DPtW, 0.21-0.23 mm; DPtI, 53-58; PtH, 0.28-0.30 mm; PtNL, 0.41-0.43 mm; LPtI, 141-146 (N=5). Nontype workers belonging to a single colony from $\mathrm{N}$. Vietnam agree well with the original description $(\mathrm{Xu}$ 
$\&$ Zeng, 2000), but the following small differences are recognized in the former: petiole in view with a slight median emargination; gaster not so distinctly punctured dorsally.

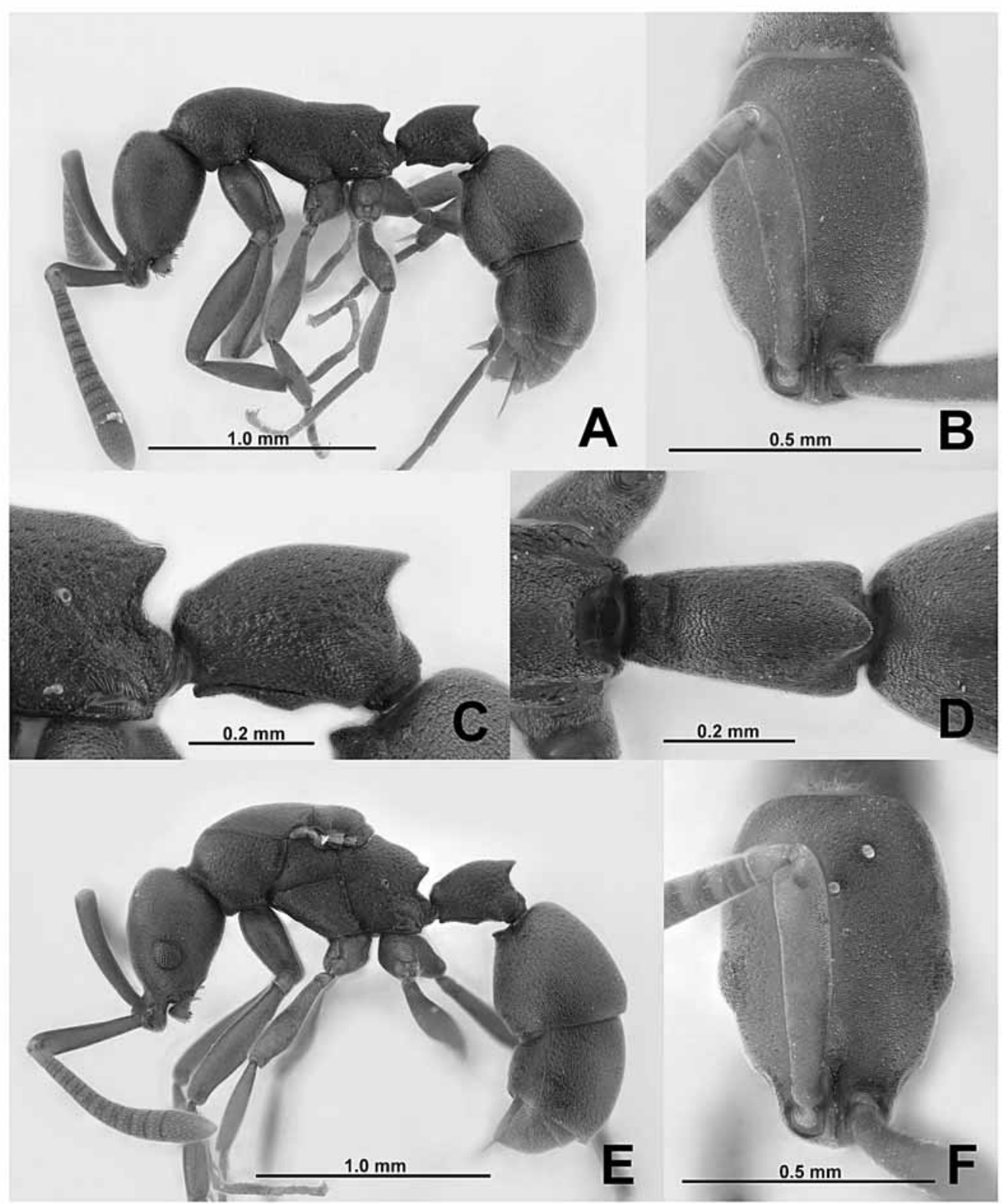

FIGURE 8. Probolomyrmex watanabei Tanaka. A-D, worker (Eg21xi05-01); E, F, queen (Eg21xi05-01). A, E, body in profile; B, F, head in full-face view; $\mathrm{C}$, petiole in profile; D, petiole in dorsal view.

Queen (teneral alate queen). HL, 0.75-0.76 mm; HW, 0.47-0.48 mm; SL, 0.66-0.67 mm; EL, 0.15 mm; CI, 62-64; SI, 140; EI, 31-32; WL, 1.20-1.22 mm; PW, 0.44-0.46 
mm; DPtW, $0.23 \mathrm{~mm}$; DPtI, 50; PtH, 0.30-0.31 mm; PtNL, $0.41 \mathrm{~mm}$; LPtI, 132-137 ( $\mathrm{N}=2$, but $\mathrm{N}=1$ for DPtW and DPtI). Head in full-face view elongate, with weakly convex sides and almost straight occipital border. Frontal carina in profile relatively high as in the worker (Fig. 9D). Eye a little longer than the width of apical antennal segment. Antennal scape when laid backward extending beyond the level of posterior margin of lateral ocelli; relative lengths of antennal segments II-XII as in the worker (see Fig. 10D); segment III a little longer than IV; IV a little longer than broad. Pronotum large; mesoscutum ca. 1.3 times as long as broad, in profile very weakly convex, without notauli; parapsidal lines very fine; scuto-scutellar suture fine, very weakly and roundly curved posteriad; scutellum in profile with steep posterior slope; axilla poorly separated from scutellum by an obscure impression but not by a suture; mesopleuron (except in its posteriormost part) well divided by a suture into anepisternum and katepisternum; raised median portion of metanotum with gentle lateral slopes; suture between metepisternum and propodeum absent; a deep depression present dividing metepisternum into anepisternum and katepisternum; orifice of metapleural gland small, opening posterolaterad; posterior margin of dorsum of propodeum in dorsal view moderately concave; posterior face of propodeum margined laterally with a carina which forms a triangular propodeal spine; outline from propodeal spine to propodeal lobe in profile weakly concave. Petiole including subpetiolar process much longer than high, in profile with weakly concave posterior outline (above the articulation with gaster), in dorsal view weakly widened around midlength; posterodorsal margin of petiolar node in dorsal view with a shallow median emargination/concavity; subpetiolar process inconspicuous, only with an acute anterior projection. Abdominal segment III (gastral segment I) in profile relatively short, gently narrowed anteriad in the anterior 3/4. Wing structure and venation as in the male. Hind wing with three hamuli.

Male. HL, $0.54 \mathrm{~mm}$; HW, $0.58 \mathrm{~mm}$; CI, 107; HD, $0.50 \mathrm{~mm}$; HDI, 93; EL, $0.28 \mathrm{~mm}$; SL, $0.41 \mathrm{~mm}$; SI, 71; MstlL, $0.20 \mathrm{~mm}$; MstlW, $0.20 \mathrm{~mm}$; MstlI, 100; WL, $1.13 \mathrm{~mm}$; PtNL, $0.39 \mathrm{~mm}$; PtH, $0.27 \mathrm{~mm}$; LPtI, $144(\mathrm{~N}=1)$. Head in lateral view relatively thick (HDI>90.00); protrusion of frontoclypeal region relatively long so that antennal insertion is situated in the middle of its dorsal surface. Frontal carina high, and distinctly exceeding posterior margin of antennal insertions in full-face view. Eye relatively broad, strongly widened ventrally. Antennal flagellum relatively long, filiform; antennal segment III distinctly longer than segment II; segment XI (the third from apex) distinctly longer than broad; ventrolateral surface of the apical segment not concave. Mandible elongatedtriangular, with only a single strong apical tooth on its masticatory margin; basal angle rounded and indistinct. Palpal formula: maxillary 4, labial 2; maxillary palp moderately long; the third palpomere distinctly longer than the second, the apical distinctly longer than the third. Pronotum in profile distinctly higher than mesoscutum; metanotum moderately produced posteriorly, and a suture separating it from mesoscutellum weakly notched; anepisternum of metapleuron separated from metakatepisternum and propodeum by a deep furrow; a suture between metakatepisternum and propodeum very weak, unclear; dorsal margin of the propodeum forming a weak angle with the posterior slope. 


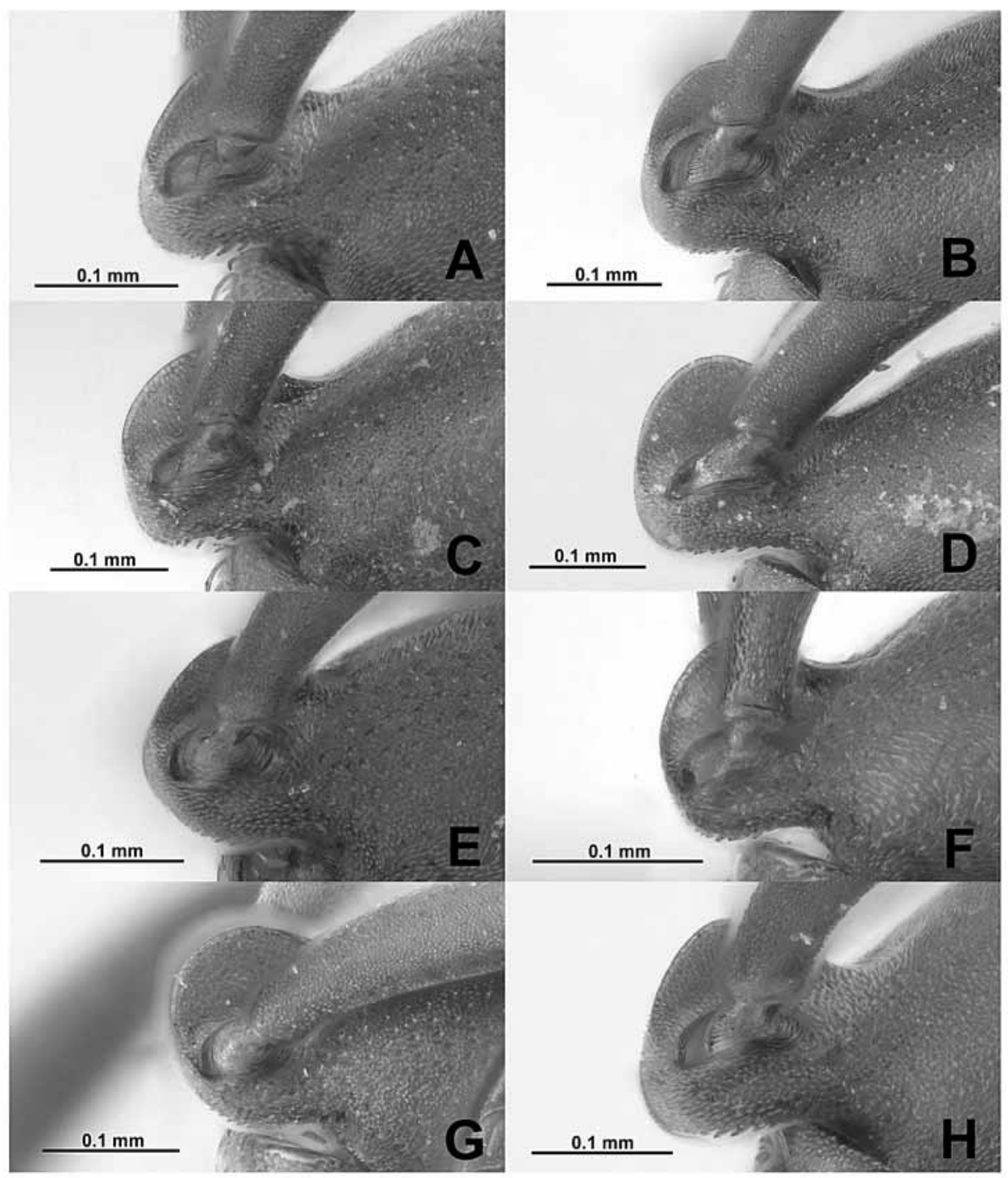

FIGURE 9. Frontoclypeal region of the workers in profile. A, Probolomyrmex dammermani Wheeler (JV04-SKY-12); B, P. itoi sp. nov. (type series); C, P. longinodus Terayama et Ogata (holotype); D, P. longiscapus Xu et Zeng (Eg09vi05-18); E, P. maryatiae sp. nov. (type series); F, $P$. okinawensis Terayama et Ogata (holotype); G, P. vieti sp. nov. (type series); H, P. watanabei Tanaka (Eg21xi05-01).

With the mesosoma in dorsal view, mesonotum lacking notauli; parapsidal lines distinct; axillae distinct; mesoscutellum broader than long; declivitous face of the propodeum very slightly concave with weak, obtuse lateral lamellae. Petiole in lateral view without a distinct peduncle; its node long with gentle anterior slope and steep posterior slope; posterodorsal margin angular; subpetiolar process narrowly developed and its apex sharp. Abdominal sternum IX long; its apical margin gently pointed medially. Genitalia retractile. With the phallus in lateral view, the basal ring moderately long and its dorsal margin 
gentle; basiparamere with the dorsal margin gently raised in its basal portion, and posterodorsal margin angular; digitus volsellaris simply curved ventrally in its apical portion; penis valve distinctly narrowed apically; its apical portion relatively sharp and slightly curved ventrally. Paramere thin; its expanded inner faces directed ventrally with the apical portion not curved dorsally. Aedeagal apodeme relatively broad. On fore wing, costa and radius apical to stigma vestigial; Rsf 2 and Rsf 3 completely absent; radial sector never reaching costal margin; Mf1, Rs+M and media apical to Rs+M present; cu-a cross vein present. On hind wing, Rsf4+5 present; jugal lobe absent.

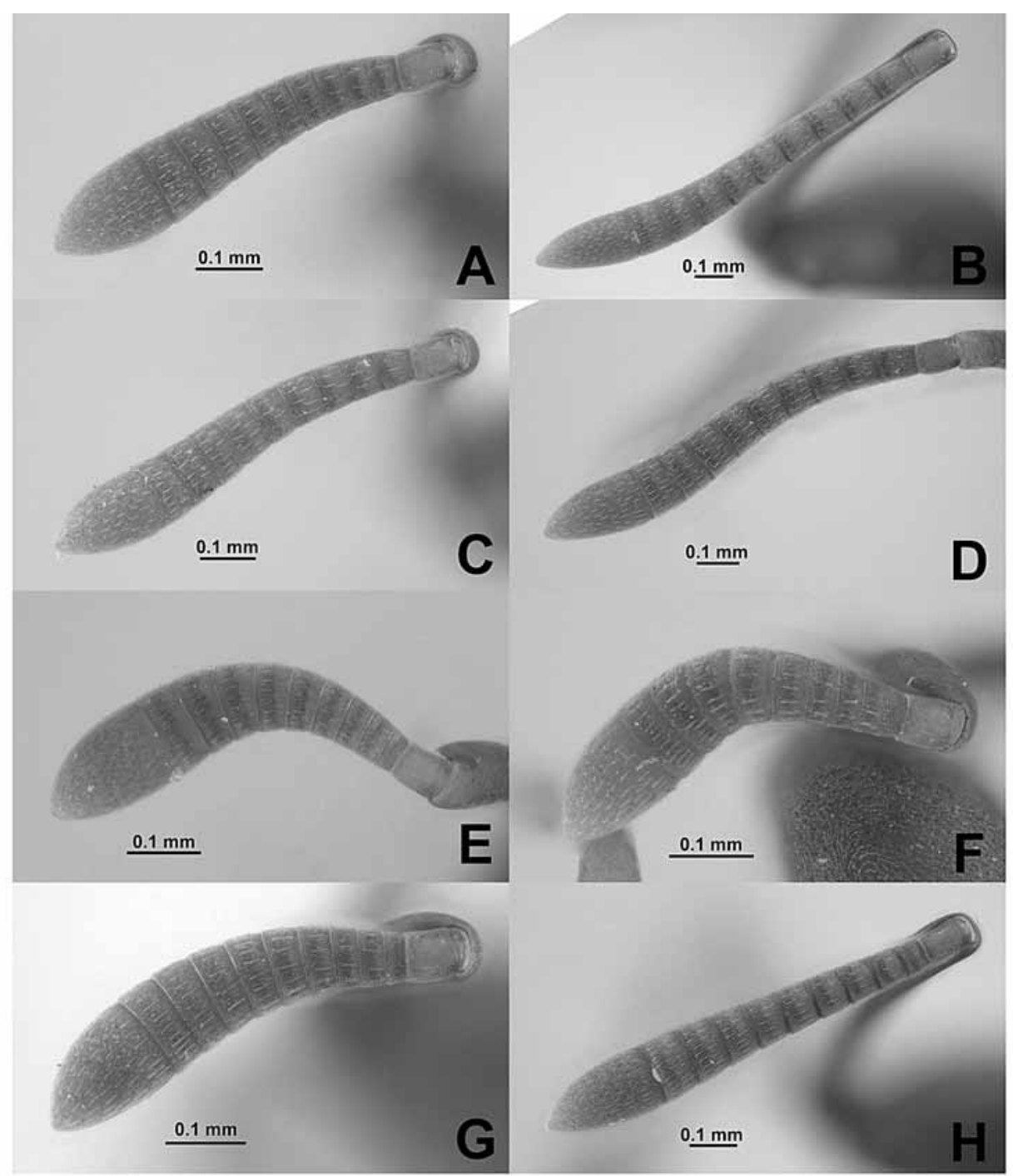

FIGURE 10. Left antenna of the workers. A, Probolomyrmex dammermani Wheeler (JV04-SKY12); B, P. itoi sp. nov. (type series); C, P. longinodus Terayama et Ogata (holotype); D, P. longiscapus Xu et Zeng (Eg09vi05-18); E, P. maryatiae sp. nov. (type series); F, P. okinawensis Terayama et Ogata (paratype from Chibana, Okinawa-hontou); G, $P$. vieti sp. nov. (type series); H, P. watanabei Tanaka (Eg21xi05-01). 


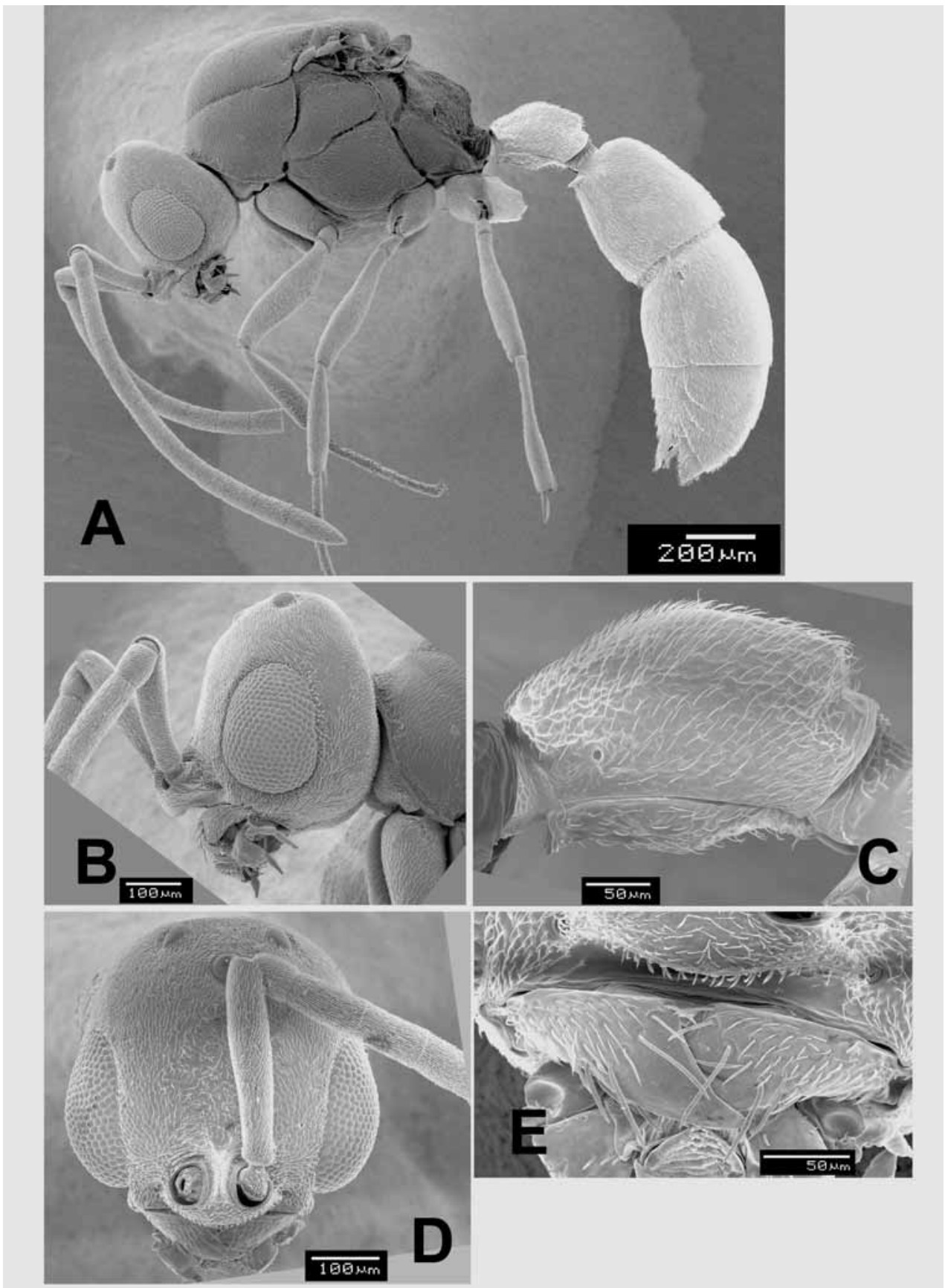

FIGURE 11. Male of Probolomyrmex dammermani Wheeler (FI95-517). A, head to abdomen in lateral view; B, head in lateral view; $\mathrm{C}$, petiole in lateral view; $\mathrm{D}$, head in full-face view; $\mathrm{E}$, mandibles in oblique ventral view. 

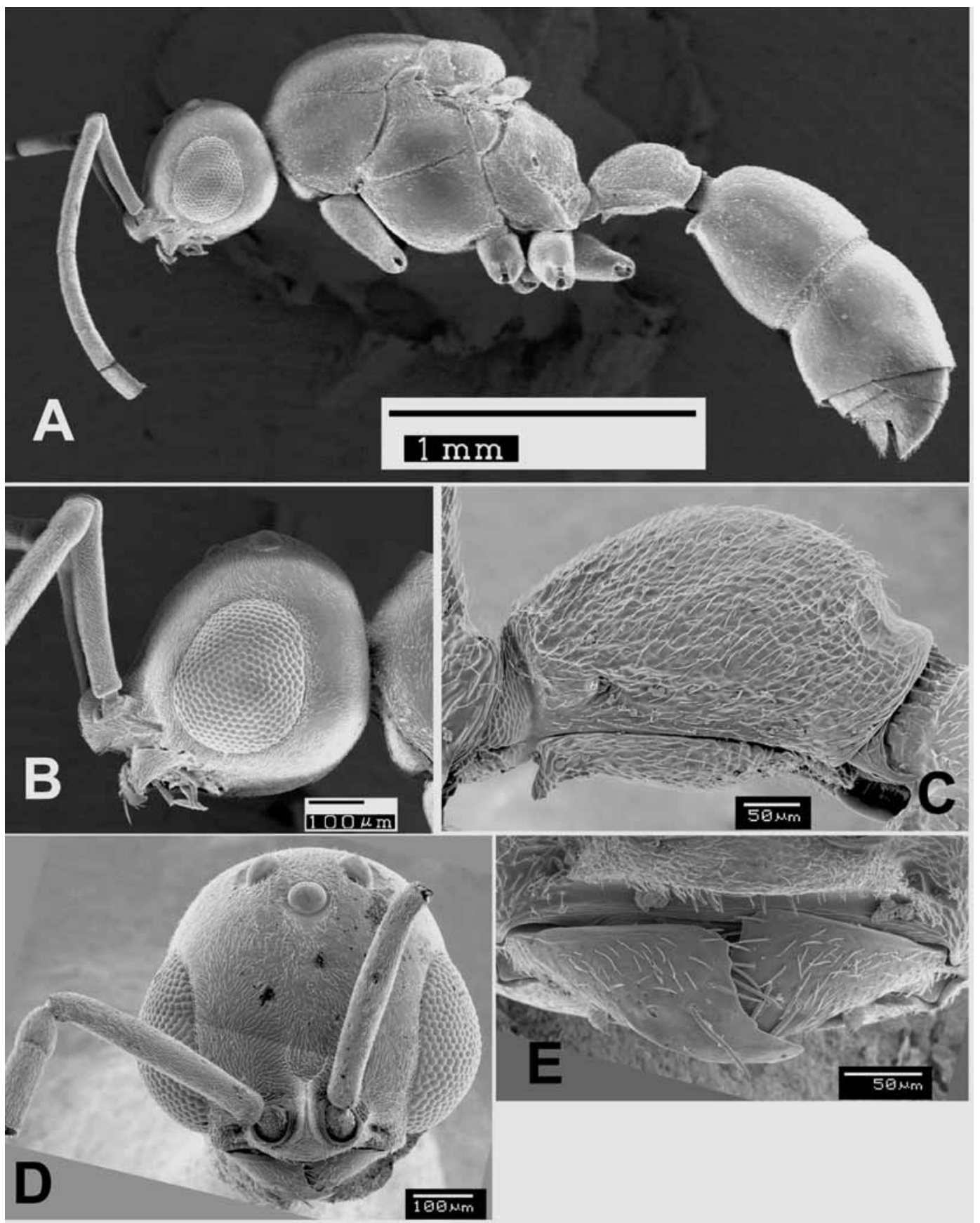

FIGURE 12. Male of Probolomyrmex longinodus Terayama et Ogata (MY945-1). A, head to abdomen in lateral view; B, head in lateral view; $\mathrm{C}$, petiole in lateral view; D, head in full-face view; E, mandibles in oblique ventral view. 


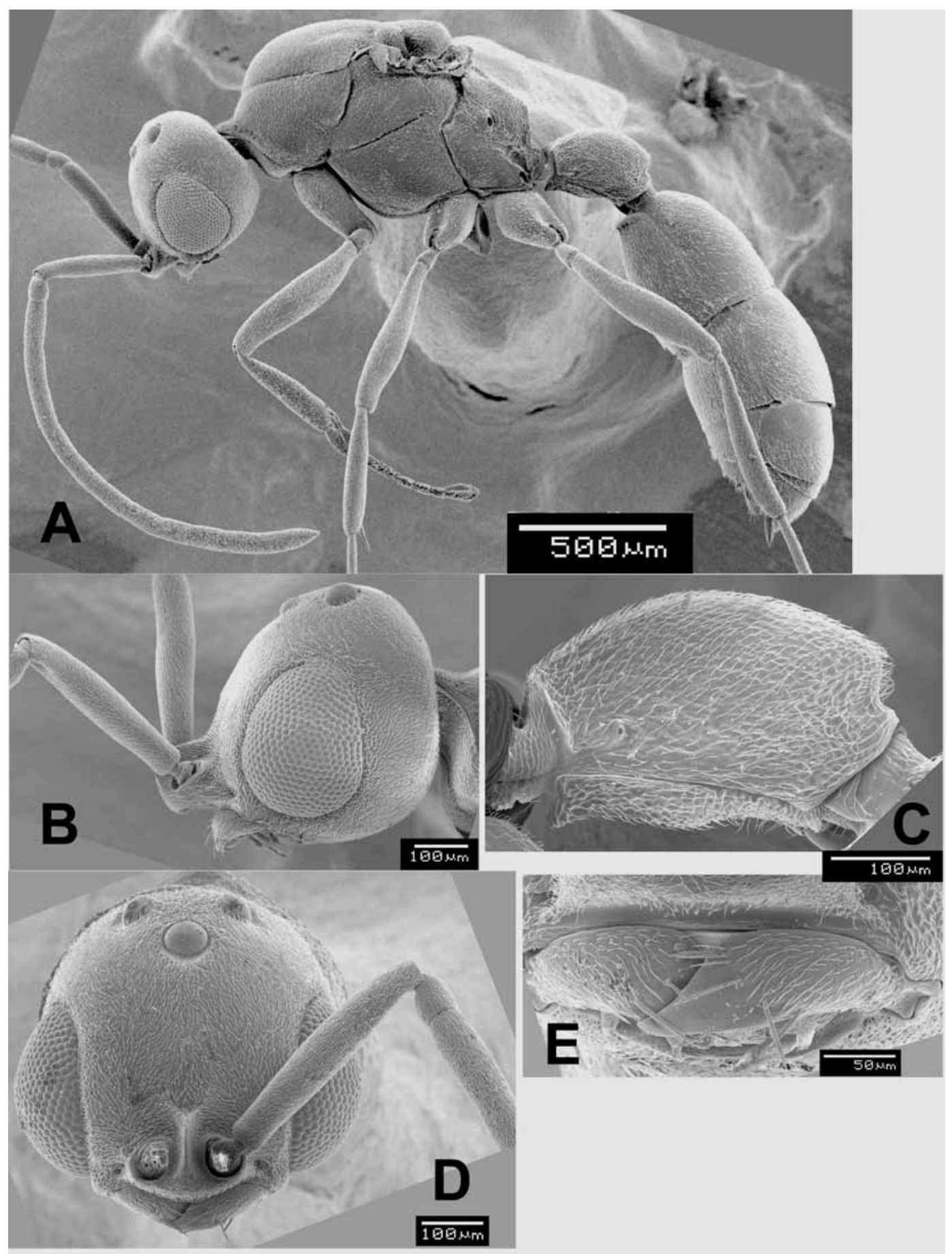

FIGURE 13. Male of Probolomyrmex longiscapus Xu et Zeng (Eg09vi05-18). A, head to abdomen in lateral view; B, head in lateral view; C, petiole in lateral view; D, head in full-face view; E, mandibles in oblique ventral view. 


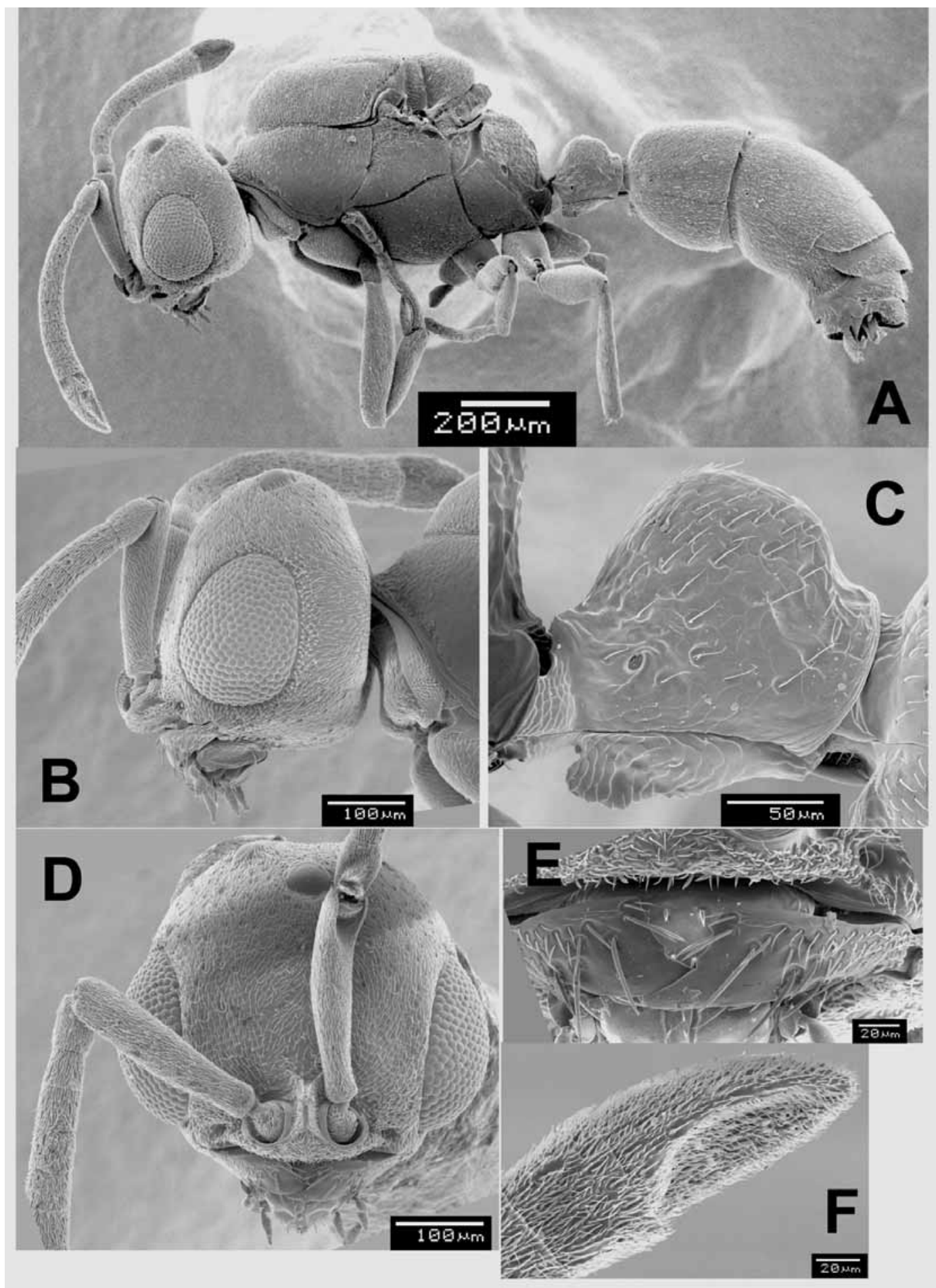

FIGURE 14. Male of Probolomyrmex vieti, sp. nov. (FI, i/1993). A, head to abdomen in lateral view; B, head in lateral view; C, petiole in lateral view; $\mathrm{D}$, head in full-face view; E, mandibles in oblique ventral view; F, apical antennal segments in oblique ventral view. 
Recognition. In the worker and queen, $P$. longiscapus is most similar to $P$. longinodus Terayama et Ogata (see under $P$. longinodus), and relatively similar to $P$. watanabei. It is well separated from $P$. watanabei by the posterodorsal margin of petiole not produced medially and antennal segment III a little longer than IV in the worker and queen. In the male, $P$. longiscapus is also very similar to $P$. longinodus, but the former can be separated from the latter by the following characteristics: 1) distinctly elongate mandibles, without teeth other than an apical tooth on the masticatory margin, 2) shorter and broader apical segment of maxillary palp, 3) steeper posterior slope of petiolar node and angular posterodorsal corner of the node, 4) weaker protrusion of metanotum in lateral view.

Distribution. China (Yunnan) and N. Vietnam.

\section{Probolomyrmex maryatiae sp. nov.}

(Figs. 5A-D, 9E, 10E)

Holotype: worker belonging to colony Eg97-BOR-587, Gunong Rara, Sabah, Malaysia, 25/ii/1997, Eg (ITBC). Paratypes: 4 workers from the same colony to which the holotype belongs (MCZC, MHNG, ACEG, SKYC).

Nontype material examined. MALAYSIA: Sabah: Sepilok Forest [general coll.: SKY 27/viii/1995]; Sarawak: Tower Region, Lambir N. P., Miri [general coll.: SKY, 15/i/1993, 1/iii/1997]. Eguchi's informal species code "Probolomyrmex sp. eg-4" applies to this species.

Worker. HL, 0.54-0.58 mm; HW, 0.35-0.36 mm; SL, 0.33-0.37 mm; CI, 60-67; SI, 92-106; WL, 0.75-0.84 mm; PW, 0.26-0.29 mm; DPtW, 0.16-0.19 mm; DPtI, 61-66; PtH, 0.26-0.29 mm; PtNL, 0.25-0.29 mm; LPtI, 96-104 (N=5). Body ferruginous brown. Head in full-face view with weakly convex sides and very shallowly concave occipital border. Eye absent. Antenna relatively short; relative lengths of antennal segments II-XII as seen in Fig. 10E; antennal segment III shorter than IV. Dorsal outline of mesosoma almost straight; posterior margin of propodeal dorsum in dorsal view strongly concave; posterior face of propodeum margined laterally with a well-developed translucent lamella which in profile forming an obtuse angle in upper portion. Petiole including subpetiolar process as long as or a little longer than high, in profile with relatively gentle anterior slope and (weakly) concave posterior outline (above the articulation with gaster); posterodorsal margin of petiolar node in dorsal view weakly and broadly concave; subpetiolar process developed, with conspicuous anteroventral and posteroventral projections; the anteroventral projections relatively thick and not translucent. Abdominal segment III (gastral segment I) in profile relatively short, relatively gently narrowed anteriad in the anterior 3/4; abdominal sternum III weakly convex behind the midlength.

Recognition. Four Oriental and Australian species are morphologically very similar to each other: this species, $P$. greavesi Taylor, $P$. salomonis Taylor, and $P$. vieti sp. nov. The difference between this species and $P$. vieti is given in the key. It is separated from $P$. greavesi as follows: in the worker the petiole in profile has a relatively steep anterior slope 
and straight posterior outline (above the articulation with gaster). Probolomyrmex maryatiae is barely separated from P. salomonis (holotype worker deposited in MCZC was examined) as follows: in the worker of the former the anterior portion of the subpetiolar process projects strongly and the posterodorsal margin of the petiolar node is relatively broadly concave. In contrast, in the worker of $P$. salomonis the anteroventral portion of the subpetiolar process forms a round corner and the posterodorsal margin of the petiolar node is relatively narrowly concave.

Distribution. Known only from Borneo.

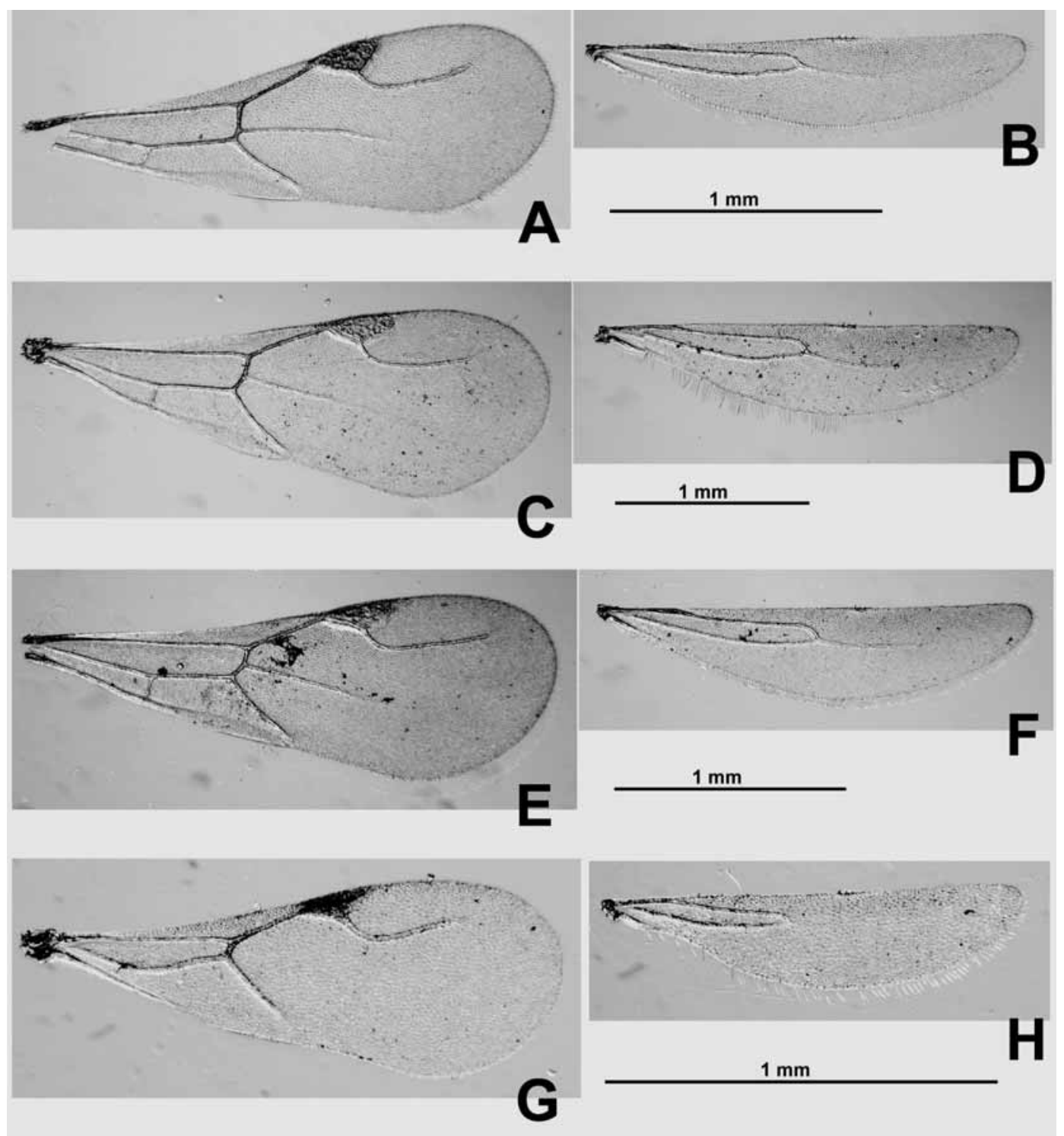

FIGURE 15. Wings of the males. A, B, Probolomyrmex dammermani Wheeler (FI95-517); C, D, P. longinodus Terayama et Ogata (MY945-1); E, F, P. longiscapus Xu et Zeng (Eg09vi05-18); G, H, P. vieti sp. nov. (FI, i/1993). A, C, E, G, fore wing; B, D, F, H, hind wing. 

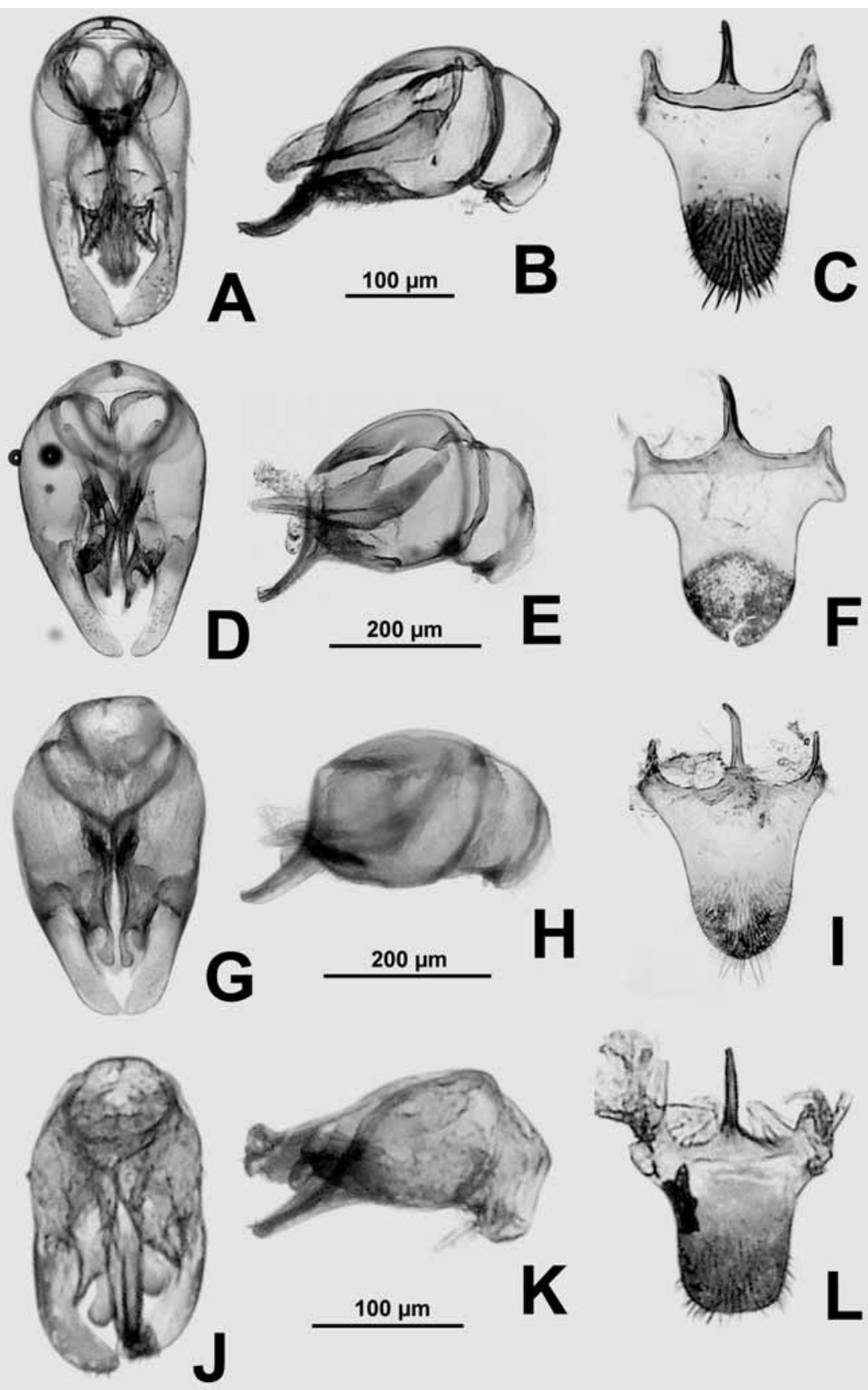

FIGURE 16. Male genitalia. A-C, Probolomyrmex dammermani Wheeler (FI95-517); D-F, $P$. longinodus Terayama et Ogata (MY945-1); G-I, P. longiscapus Xu et Zeng (Eg09vi05-18); J-L, P. vieti sp. nov. (FI, i/1993). A, D, G, J, in ventral view; B, E, H, K, in lateral view; C, F, I, L, abdominal sternum IX in ventral view. 
Probolomyrmex okinawensis Terayama et Ogata, 1988: 591-592, figs. 1-5. Holotype: worker, Chibana, Okinawa-hontou Is. [Okinawa-jima], Ryukyus, Japan, 19/iii/1983, T. Mizutani (Faculty of Agriculture, Kyushu Univ., Japan) [examined]. Paratypes: 4 workers from the same nest as the holotype [one paratype examined (loaned from the Institute of Tropical Agriculture, Kyushu Univ.)]; 1 dealate queen and 1 worker, Nakasone, Okinawa-hontou Is., 20/xi/1975, T. Abe [not examined]; 1 dealate queen from Nakijin-joushi, Okinawa-hontou Is., 7/iii/1984, K. Onoyama [examined (loaned from the Institute of Tropical Agriculture, Kyushu Univ.)].

Recognition. This species is similar to $P$. maryatiae sp. nov. and $P$. vieti sp. nov., but distinguished from the latter two by the posteroventral portion of subpetiolar process forming only an obtuse angle in the worker and queen.

Distribution. Known only from Okinawa-jima (C. Ryukyus).

\section{Probolomyrmex procne Brown}

Probolomyrmex procne Brown, 1975: 56-57, figs. 8, 10. Holotype: worker from Palni Hills, $650 \mathrm{~m}$ alt., $39 \mathrm{~km}$ E of Kodaikanal, Madras State, India, 11/xi/1972, Besuchet, Löbi \& Mussard (MHNG) [not examined].

Recognition. This species is similar to $P$. dammermani Wheeler and $P$. longinodus Terayama et Ogata, but is well characterized by its petiolar node in dorsal view widened posteriad and ending as paired acute angles posterodorsally in the worker. Sexual forms are unknown.

Distribution. Known only from the type locality.

Probolomyrmex vieti sp. nov.

(Figs. 7A-F, 9G, 10G, 14A-F, 15G, H, 16J-L)

Probolomyrmex sp. 1: Ito et al., 2001: 403 (species list).

Holotype: worker belonging to colony Eg04-VN-783, South Cat Tien N. P. (behind the headquarters, < $160 \mathrm{~m}$ alt.), Dong Nai, S. Vietnam, 23/x/2004, Eg (IEBR). Paratypes: 7 workers from the same colony to which the holotype belongs (MCZC, MHNG, ACEG, SKYC).

Nontype material examined. THAILAND: Nakhonratchasima: Khao Yai N. P. [general coll.: SKY, 29/v/2000]; INDONESIA: W. Java: Kebun Raya, Bogor [general coll.: FI, i/1993 (including male); colony: FI92-305 (including queen), FI93-60 (including queen)]. Eguchi's informal species code "Probolomyrmex sp. eg-2" and Yamane's "Probolomyrmex sp. 3" apply to this species. 
Worker. HL, 0.51-0.57 mm; HW, 0.33-0.35 mm; SL, 0.29-0.35 mm; CI, 61-65; SI, 88-100; WL, 0.69-0.79 mm; PW, 0.25-0.28 mm; DPtW, 0.16 mm; DPtI, 57-64; PtH, 0.25-0.27 mm; PtNL, 0.21-0.25 mm; LPtI, 78-100 (N=5). Body ferruginous brown. Head in full-face view with weakly convex sides and very shallowly concave occipital border. Eye absent. Antenna relatively short; relative lengths of antennal segments II-XII as in Fig. 10G; segment III shorter than IV. Dorsal outline of mesosoma straight; posterior margin of dorsum of propodeum in dorsal view moderately concave; posterior face of propodeum margined laterally with a well-developed translucent lamella which in profile is weakly produced posteriad but not forming a conspicuous propodeal spine. Petiole including subpetiolar process a little higher than long, in profile with relatively steep anterior slope and straight posterior outline (above the articulation with gaster); posterodorsal margin of petiolar node in dorsal view almost straight (very weakly concave medially in a specimen from Thailand); subpetiolar process developed; its anteroventral portion with a translucent projection/lobe which extends anteroventrad and often with a narrow apex; posteroventral portion of subpetiolar process forming an angle. Abdominal segment III (gastral segment I) in profile relatively short, gently narrowed anteriad in the anterior 2/3; abdominal sternum III weakly (in the type series) or very weakly (in the worker from Indonesia) convex behind the midlength.

Queen (based on nontype dealate and teneral alate queens). HL, $0.51 \mathrm{~mm}$; HW, 0.35 mm; SL, $0.30 \mathrm{~mm}$; EL, $0.09 \mathrm{~mm}$; CI, 69; SI, 86; EI, 26; WL, $0.74 \mathrm{~mm}$; PW, $0.27 \mathrm{~mm}$; DPtW, $0.16 \mathrm{~mm}$; DPtI, 59; PtH, $0.26 \mathrm{~mm}$; PtNL, $0.20 \mathrm{~mm}$; LPtI, 77 (N=1). Body ferruginous brown. Head in full-face view elongate, with very weakly convex sides and almost straight or very weakly concave occipital border. Eye shorter than the width of apical antennal segment. Antenna relatively short; scape when laid backward at most reaching the level of anterior margin of median ocellus; relative lengths of antennal segments II-XII as in the worker (see Fig. 10G); segment III shorter than IV. Pronotum large; mesoscutum ca. 1.25-1.35 times as long as broad, in profile very weakly convex; notauli absent; parapsidal lines very fine; scuto-scutellar suture fine, very weakly and roundly curved posteriad; scutellum in profile with relatively gentle posterior slope; axilla poorly separated from scutellum by an obscure impression but not by suture; mesopleuron fully divided by a suture into anepisternum and katepisternum (but suture sometimes absent in its posteriormost part); median portion of metanotum abruptly raised with the dorsum small in size and almost rectangular in shape; suture between metepisternum and propodeum absent; a weak depression present dividing metepisternum into anepisternum and katepisternum; orifice of metapleural gland small, opening posterolaterad; posterior margin of propodeal dorsum in dorsal view moderately and broadly concave; posterior face of propodeum margined laterally with a well-developed translucent lamella which in profile is weakly produced posteriad but not forming a conspicuous propodeal spine in upper portion. Petiole including subpetiolar process a little higher than long, in profile with relatively steep anterior slope and straight posterior outline (above the articulation 
with gaster); posterodorsal margin of petiolar node in dorsal view almost straight; subpetiolar process developed; the anteroventral portion of the process more or less projecting or at least forming a round corner, and the posteroventral portion forming an angle; ventral edge of the process thin. Abdominal segment III (gastral segment I) in profile short, gently narrowed anteriad in the anterior $2 / 3$; abdominal sternum III very weakly convex behind the midlength. Wing structure and venation as in the male. Hind wing with three hamuli.

Male. HL, 0.39-0.41 mm; HW, 0.43-0.45 mm; CI, 110; HD, 0.34 mm; HDI, 83-87; EL, $0.20 \mathrm{~mm}$; SL, $0.24 \mathrm{~mm}$; SI, 53-56; MstlL, $0.16 \mathrm{~mm}$; MstlW, $0.16 \mathrm{~mm}$; MstlI, 100; WL, $0.75 \mathrm{~mm}$; PtNL, 0.16-0.18 mm; PtH, 0.17-0.18 mm; LPtI, 94-100 (N=2, but N=1 for WL). Head in lateral view relatively thin $(\mathrm{HDI}<90)$; protrusion of the frontoclypeal region relatively short so that antennal insertion is situated on apical portion of its dorsal surface. Frontal carina high, distinctly exceeding posterior margin of antennal insertions in fullface view. Eye moderately widened ventrally. Antennal flagellum relatively short, slightly widened apically; antennal segment III shorter than segment II; segment XI (the third from apex) broader than long; ventrolateral surface of the apical segment widely and strongly concave. Mandible elongate-triangular, with two small dents and a single strong apical tooth on its masticatory margin; the basal angle distinct. Palpal formula: maxillary 4, labial 2; maxillary palp relatively short; the third palpomere short, slightly longer than the second, and the apical distinctly longer than the third. Pronotum in profile slightly higher than mesoscutum; metanotum moderately produced posteriorly, and a suture separating it from mesoscutellum strongly notched; anepisternum of metapleuron separated from metakatepisternum and propodeum by a deep furrow; metakatepisternum clearly separated from propodeum; dorsal margin of propodeum rounded, not forming a distinct angle with the posterior slope. With the mesosoma in dorsal view, mesonotum lacking notauli; parapsidal lines distinct; axillae distinct; mesoscutellum longer than broad; declivitous face of propodeum not concave, edged laterally with weak sculpture. Petiole in lateral view with a short peduncle differentiated from node; node distinctly shortened, with steep anterior slope and gentle posterior slope; posterodorsal margin rounded; subpetiolar process broadly developed and its apex blunt. Abdominal sternum IX short; its apical margin transversely flat, not pointed medially. Genitalia not retractile. With the phallus in lateral view, the basal ring moderately long and its dorsal margin nearly straight; basiparamere with the dorsal margin suddenly raised in its basal portion, and posterodorsal slope gentle; digitus volsellaris simply curved ventrally in its apical portion; cuspis volsellaris broadly developed; penis valve wide and nearly straight, and its apical portion blunt. Paramere thin; its expanded inner faces directed ventrally, with its apical portion not curved. On fore wing, costa and radius apical to stigma vestigial; Rsf2 and Rsf3 completely absent; radial sector never reaching costal margin; Mf1, Rs+M and media apical to Rs+M completely absent; cu-a cross vein absent. On hind wing, Rsf4+5 vestigial; jugal lobe absent. 
Recognition. In the worker, this species is barely separated from P. greavesi Taylor described from Capital Territory and S. Queensland, Australia (1 paratype worker and 1 paratype queen deposited in MCZC were examined), but the anteroventral portion of subpetiolar process projects anteroventrad in the worker of $P$. vieti. In the male, this species is rather clearly separated from $P$. greavesi by 1 ) masticatory margin of mandible with two teeth in addition to apical tooth, 2) dorsal margin of the node that is declining posteriorly and clearly divided from anterior and posterior faces, and 3) a broad and strong ventrolateral concavity on the apical segment of antenna.

Distribution. Known from the Indo-Chinese Peninsula and Java.

\section{Probolomyrmex watanabei Tanaka}

(Figs. 8A-F, 9H, 10H)

Probolomyrmex watanabei Tanaka, 1974: 35-37, figs. 1-7. Holotype: worker, Pasoh Forest, Malaysia, 15/i/1972, H. Watanabe (Tanaka's private collection) [not examined].

Nontype material examined. MALAYSIA: Kedah: Gunung Jerai (05 47'17'N, $106^{\circ} 26^{\prime} 06^{\prime} \mathrm{E}, 760-1170 \mathrm{~m}$ alt.) [colony: Eg21xi05-01 (including queen)]; Selangor: Ulu Gombak [colony: FI98-76].

Worker. HL, 0.64-0.72 mm; HW, 0.42-0.45 mm; SL, 0.52-0.60 mm; CI, 62-66; SI, 124-135; WL, 0.96-1.10 mm; PW, 0.33-0.38 mm; DPtW, 0.19-0.22 mm; DPtI, 57-60; PtH, 0.23-0.28 mm; PtNL, 0.34-0.40 mm; LPtI, 132-148 ( $\mathrm{N}=6)$. Nontype workers examined here agree well with the original description (Tanaka, 1974). Palp formula also agrees with the holotype but we have not yet examined mandible and mouthparts in detail because only a few specimens are available.

Queen (dealate queen). HL, $0.69 \mathrm{~mm}$; HW, $0.46 \mathrm{~mm}$; SL, $0.57 \mathrm{~mm}$; EL, $0.14 \mathrm{~mm}$; CI, 67; SI, 124; EI, 30; WL, 1.12 mm; PW, $0.41 \mathrm{~mm}$; DPtW, 0.23 mm; DPtI, 56; PtH, 0.28 $\mathrm{mm}$; PtNL, $0.38 \mathrm{~mm}$; LPtI, $136(\mathrm{~N}=1)$. Body ferruginous brown; apical three segments of gaster yellowish. Head in full-face view with weakly convex sides and almost straight occipital border. Eye as long as the width of apical antennal segment. Antenna moderately long; scape when laid backward just reaching the level of anterior margin of lateral ocelli; relative lengths of antennal segments II-XII as in the worker (see Fig. 10H); segment III shorter than IV. Pronotum large; mesoscutum ca. 1.2 times as long as broad, in profile very weakly convex, without notauli; parapsidal lines fine but distinct; scuto-scutellar suture fine, very weakly and roundly curved posteriad; scutellum in profile with relatively steep posterior slope; axilla poorly separated from scutellum by an obscure impression but not by suture; mesopleuron (except its posteriormost part) well divided by a suture into anepisternum and katepisternum; metanotum with its median portion only weakly raised and laterally gently sloping; suture between metepisternum and propodeum absent; a distinct depression present metepisternum into anepisternum and katepisternum; orifice of 
metapleural gland small, opening posterolaterad; posterior margin of propodeal dorsum in dorsal view moderately concave; posterior face of propodeum margined laterally with a well-developed lamella which forms a triangular propodeal spine; outline from propodeal spine to propodeal lobe in profile strongly concave. Petiole including subpetiolar process much longer than high, in profile with strongly concave posterior outline (above the articulation with gaster), in dorsal view weakly widened posteriad, with the broadest point just before the posterior end; posterodorsal margin of petiolar node in dorsal view produced medially; subpetiolar process very poorly developed. Abdominal segment III (gastral segment I) in profile relatively strongly narrowed anteriad in the anterior $2 / 3$; abdominal sternum III in profile rather strongly convex behind its midlength.

Recognition. This species is well separated from related species by the following characteristics in the worker and queen: posterodorsal margin of petiolar node in dorsal view produced medially, and abdominal segment III in profile relatively strongly narrowed anteriad in the anterior 2/3. This species is most similar to P. longiscapus Xu et Zeng (see under P. longiscapus).

Distribution. Known only from Southern Malay Peninsula.

\section{Discussion}

Two species groups, the longinodus group and the greavesi group, can be recognized based on worker morphology among ten Oriental species and two Australian species that are dealt with or discussed in the present study. The longinodus group is characterized by the petiole which is clearly longer than high, and subpetiolar process which is low with poorly developed posteroventral portion. Probolomyrmex dammermani, P. itoi, $P$. longinodus, P. longiscapus, $P$. procne and $P$. watanabei are included here. They are separated from each other by SI, LPtI, development of propodeal spine, shape of posterodorsal portion of petiole, and/or shape of abdominal segment III in profile. The greavesi group is characterized by the petiole which is at most a little longer than high, and subpetiolar process which is developed and somewhat rectangular. Probolomyrmex bidens, $P$. greavesi, $P$. maryatiae, $P$. okinawensis, $P$. salomonis and $P$. vieti belong to this species group. Probolomyrmex bidens, in which the petiolar node has paired teeth posterodorsally, and P. okinawensis, in which the posteroventral portion of subpetiolar process forms an obtuse angle only, are relatively well distinguished from the other members of the greavesi group. On the other hand, $P$. greavesi, $P$. maryatiae, $P$. salomonis and $P$. vieti are only barely separated from each other based on worker morphology (see under P. maryatiae and $P$. vieti). There are two possible views for this morphological similarity: they are geographical variants of a single variable species ranging from IndoChina to Australia and Solomon, or biological species with slight morphological differentiation. However, male morphology strongly supports the separation of $P$. greavesi from $P$. vieti at species level. Although more information is needed particularly for male 
characters of the other forms, we have inclined to the second view and described $P$. maryatiae and $P$. vieti as sibling species of $P$. salomonis and $P$. greavesi.

Male morphology supports the recognition of the two species groups. In the male of the longinodus group (P. dammermani, P. longinodus and P. longiscapus), the protrusion of the frontoclypeal region is relatively long, so that antennal insertion is situated in the middle of its dorsal surface; the third antennal segment is distinctly longer than the second; Mf1, Rs+M and media apical to Rs+M are present; cu-a cross vein is present; petiolar node is long and has a gentle anterior slope; median portion of the ninth abdominal sternum is strongly and roundly expanded apicad; genitalia are retractile. On the other hand, in the male of the greavesi group (P. vieti), the protrusion of the frontoclypeal region is relatively short, so that antennal insertion is situated in apical portion of its dorsal surface; the third antennal segment is shorter than the second; Mf1, Rs+M and media apical to Rs+M are completely absent; cu-a cross vein is absent; petiolar node is very short and has a steep anterior slope; median portion of the ninth abdominal sternum is moderately expanded apicad and has an almost straight apical margin; genitalia are not retractile.

\section{Acknowledgments}

We would like to thank Dr. Bui Tuan Viet (IEBR), Dr. Maryati Mohamed (ITBC), Dr. Idris Abd. Ghani (Universiti Kebangsaan Malaysia), Mr. Ruslan Md. Yusop (Universiti Kebangsaan Malaysia), Mr. Rosichon Ubaidillah (Indonesian Institute of Sciences, Indonesia) and Mr. Syaukani (Syiah Kuala University, Indonesia / Kagoshima Univ., Japan) who provisioned K. Eguchi with every facility for his collection trips, Dr. Fuminori Ito (Kagawa University, Japan), Dr. Mamoru Terayama (University of Tokyo, Japan), Dr. Keiichi Onoyama (Obihiro City, Japan) and Dr. Tomonori Kikuchi (University of the Ryukyus, Japan) who provided us precious material as gifts or on loan, and Dr. Osamu Tadauchi (Kyushu University, Japan), Dr. Kazuo Ogata (Kyushu Univ.) and Dr. Satoshi Kamitani (Kyushu Univ.) who arranged the type material for us. K. Eguchi wishes to thank Dr. Stefan Cover (MCZC) and Dr. Gary D. Alpert (Harvard University) who provisioned every facility for him during his stay in MCZC. K. Eguchi's research was supported by the Research Fellowships of the Japan Society for the Promotion of Science for Young Scientists, and M. Yoshimura's research by a Grant-in-Aid for JSPS Fellows (No. 175904 to M. Yoshimura).

\section{References}

Agosti, D. (1995) A revision of the South American species of the ant genus Probolomyrmex (Hymenoptera: Formicidae). Journal of the New York Entomological Society, 102, 429-434 
Bolton, B. (1995) A new general catalogue of the ants of the world. Harvard University Press, Cambridge, Massachusetts and London, England, 504 pp.

Bolton, B. (2003) Synopsis and classification of Formicidae. Memoirs of the American Entomological Institute, 71, $370 \mathrm{pp}$.

Brown, W.L.,Jr. (1975) Contributions toward a reclassification of the Formicidae. V. Ponerinae, tribes Platythyreini, Cerapachyini, Cylindromyrmecini, Acanthostichini, and Aenictogitini. Search Agriculture, Ithaca, 15, 1-115.

Ito, F., Yamane, Sk., Eguchi, K., Woro A. Noerdjito, Sih Kahono, Tsuji, K., Ohkawara, K., Yamauchi, K., Nishida, T. \& Nakamura, K. (2001) Ant species diversity in the Bogor Botanic Garden, W. Java, Indonesia, with descriptions of two new species of the genus Leptanilla (Hymenoptera, Formicidae). Tropics, 10, 379-404.

O'Keefe, S.T. \& Agosti, D. (1998) A new species of Probolomyrmex (Hymenoptera: Formicidae) from Guanacaste, Costa Rica. Journal of the New York Entomological Society, 105, 190-192.

Taylor, R.W. (1965) A monographic revision of the rare tropicopolitan ant genus Probolomyrmex Mayr (Hymenoptera: Formicidae). Transactions of the Royal Entomological Society of London, 117, 345-365.

Terayama, M. \& Ogata, K. (1988) Two new species of the ant genus Probolomyrmex (Hymenoptera, Formicidae) from Japan. Kontyu, 56, 590-594.

Wheeler, W.M. (1928) A new species of Probolomyrmex from Java. Psyche, 35, 7-11.

Xu, Z.H. \& Zeng, G. (2000) Discovery of the worker caste of Platythyrea clypeata Forel and a new species of Probolomyrmex Mayr in Yunnan, China (Hymenoptera: Formicidae). Entomologia Sinica, 7, 213-217. 